\title{
Does Education Make People Happy? Spotlighting the Overlooked Societal Condition
}

\author{
Satoshi Araki ${ }^{1}$ (D)
}

Accepted: 25 May 2021 / Published online: 8 June 2021

(c) The Author(s) 2021, corrected publication, 2021

\begin{abstract}
The association between education and subjective well-being has long been investigated by social scientists. However, prior studies have paid inadequate attention to the influence of societal-level educational expansion and skills diffusion. In this article, multilevel regression analyses, using internationally comparable data for over 48,000 individuals in 24 countries, detect the overall positive linkage between educational attainment and life satisfaction. Nevertheless, this relationship is undermined due to the larger degree of skills diffusion at the societal level, and no longer confirmed once labor market outcomes are accounted for. Meanwhile, the extent of skills diffusion per se is positively and substantially associated with people's subjective well-being even after adjusting for key individual-level and country-level predictors, whereas other societal conditions including GDP, Gini coefficients, safety, civic engagement, and educational expansion do not indicate significant links with life satisfaction in the current analysis. Given that recent research suggests skills diffusion promotes the formation of meritocratic social systems, one may argue it is the process of fairer rewards allocation underpinned by skills diffusion, rather than the status quo of macroeconomy, economic inequality, social stability, and educational opportunities as such, that matters more to people's subjective well-being.
\end{abstract}

Keywords Education · Skills $\cdot$ Life satisfaction $\cdot$ Happiness $\cdot$ Meritocracy $\cdot$ Multilevel analysis

\section{Introduction}

What is the function of education in our lives? This is the frequently asked question in the social sciences. Indeed, researchers have detected various outcomes of education, ranging from direct effects (i.e., development of cognitive and non-cognitive abilities) to indirect benefits such as better occupations, incomes, health, social contacts, and civic engagement at the individual level (e.g., World Bank, 2017). Furthermore, prior research has revealed that such individual-level outcomes lead to macroeconomic growth and innovation,

Satoshi Araki

satoshiaraki@ln.edu.hk

1 Department of Sociology and Social Policy, Lingnan University, 8 Castle Peak Road, Tuen Mun, New Territories, Hong Kong 
increasing tax revenues, decreasing public spending on social welfare, and promoting democracy and peace among other things (e.g., OECD, 2007).

While these positive links between education and socio-economic dimensions have been advocated, researchers have also cast doubt on such notions. In particular, in line with an epoch-making empirical study by Coleman and colleagues (Coleman et al., 1966), the vast literature has claimed education systems maintain the existing social inequality whilst depriving learners of autonomy, thus making societies less mobile (Bernstein, 1996; Bourdieu \& Passeron, 1977; Bowles \& Gintis, 1976; Foucault, 1977; Freire, 1972; Illich, 1971).

Considering these potential positive and negative consequences of education at both the individual and societal levels, scholars and policy makers have explored one pivotal question: does education contribute to happiness after all? (Bailey, 2009) This issue is of great importance to contemporary society where multidimensional well-being, rather than mere economic and material prosperity, is distinctively prioritized (Diener et al., 2010; Easterlin, 2010; Kahneman \& Deaton, 2010; OECD, 2014b, 2015; Oulton, 2012; Stiglitz et al., 2009; United Nations, 2016; van Zanden et al., 2014). Put differently, education may lose its ground unless it results in people's well-being ${ }^{1}$.

In this regard, there is almost a consensus that education enhances life satisfaction at least indirectly via gaining key determinants of happiness such as better occupations, monetary rewards, and health (Helliwell et al., 2020). However, when it comes to the direct effect of education, evidence is not monolithic. Whereas the literature reveals that education contributes to subjective well-being (SWB) even when controlling for other factors (Cuñado \& de Gracia 2012; Nikolaev, 2018; Rodríguez-Pose \& von Berlepsch, 2014; Salinas-Jiménez et al., 2011), prior studies also suggest education per se does not affect or may even undermine happiness when considering the mediation by objective socio-economic outcomes (Clark \& Oswald, 1996; Helliwell, 2003; Ngoo et al., 2015).

Although this contradictory view of the association between education and happiness is often explained as resulting from differences in research targets like countries and cohorts (Akaeda, 2019), one essential question has been inadequately explored: how does the link between education and SWB at the individual level vary in response to societal-level educational expansion? For the past few decades, social scientists have detected the diminishing power of educational attainment over socio-economic outcomes when considering its relative scarcity as positional goods. That is, as educational opportunity increases in a given society, it becomes difficult for educated people to socio-economically stand out just by possessing high credentials (Collins, 1979; Hannum et al., 2019). Given this mutable value of educational attainment, one may assume the link between individual-level education and happiness would change in accordance with societal educational expansion. However, except for some pioneering studies (e.g., Nikolaev, 2016; Salinas-Jiménez et al., 2011), little is known about how this relationship differs depending on the relative scarcity of education.

\footnotetext{
1 The scope of subjective well-being (SWB) is broad, including cognitive, affective, and eudaemonic dimensions (Diener, 2000; Möwisch et al., 2021; Tsurumi et al., 2020). Even within cognitive SWB, previous studies have argued the importance of distinguishing several concepts such as "happiness" and "life satisfaction" (e.g., Michalos, 2008; Nikolaev, 2018). While acknowledging this argument, the present paper uses these terms concerning cognitive SWB interchangeably, given that the vast literature has proved their comparability and compatibility (e.g., Frey \& Stutzer, 2002; Ruiu \& Ruiu, 2019). Nevertheless, in the empirical analysis that follows, two variables, namely "life satisfaction" and "happiness," are used respectively to verify the robustness of results and implications.
} 
Meanwhile, educational expansion as a collective condition in a given society may have a significant influence on people's SWB. This may happen, as argued by the literature, when the increase in access to higher levels of education promotes meritocratic social systems that enable individuals to feel a sense of societal fairness alongside high aspirations and hope (Marginson, 2016), resulting in an intensified satisfaction at the individual level. It is therefore imperative to pay close attention to both societal-level educational expansion as such and its interaction with individual-level education.

Herein, recent research also argues that (1) there is a discrepancy between the degree of educational expansion and that of skills diffusion, (2) the consistency level of the two conditions varies across countries, and (3) skills diffusion would promote the meritocratic resource allocation by mitigating the monetary return to educational credentials per se (Araki, 2020). This implies two things. Firstly, given that economic statuses operate as significant determinants of SWB and that skills diffusion devalues educational attainment, the overall contribution of individual-level education to SWB may decline in tandem with skills diffusion. This could in turn lead to the diminishing direct effect of education as it becomes more difficult for educated people to gain self-esteem merely by possessing high educational qualifications in a society where the share of highly skilled human resources is large. Secondly, as with educational expansion, skills diffusion as a societal condition could directly enhance people's happiness by bringing fairer social systems that people can recognize explicitly or implicitly. Thus, the influence of skills diffusion, as well as educational expansion, needs to be incorporated in analyzing whether education contributes to enhancing happiness.

Against such a backdrop, this article sheds light on the relationship between education and SWB with close attention to (1) how the influence of individuals' education varies depending on the extent of educational expansion and skills diffusion, and (2) how these two societal educational conditions as such affect happiness. Herein, one potential approach is to investigate what types of educational qualifications including prestige of education institutions and fields of study are (not) associated with happiness among what kinds of people according to their social backgrounds (e.g., gender, age, ethnicity, economic class, and geographical areas). While such analyses are meaningful, as detailed in the following sections, the present paper adopts a macrosociological cross-country approach to detect a general trend as the foundation for further investigations including country-specific analyses. Put differently, by extending the analytic framework and findings that follow, future research can further progress our understanding of the link between education and happiness with attention to social backgrounds and types of educational credentials.

In the next section, the relevant literature is reviewed, leading to some hypotheses to be tested. After explaining data and methods, analysis results are described, followed by discussions and conclusion.

\section{Education and Happiness}

Education has long been advocated as the key to realizing a better life and a better society. With higher levels of educational attainment, individuals are more likely than less educated counterparts to obtain preferable socio-economic statuses including decent occupations, higher earnings, better health, and broader networks of contacts (OECD, 2007). Given that these multidimensional outcomes have proved to enhance SWB (Helliwell et al., 2020), one may expect education also leads to happiness through such socio-economic rewards. 
Indeed, the literature has detected the overall positive association between education and well-being (Bailey, 2009; Chen, 2012; Hu, 2015; Nikolaev, 2018; Oreopoulos \& Salvanes, 2011; Powdthavee et al., 2015; Rodríguez-Pose \& von Berlepsch, 2014; Ruiu \& Ruiu, 2019; Salinas-Jiménez et al., 2013).

As regards the direct effect of education, however, evidence is varied. On the one hand, prior research has shown that education increases the level of happiness because the process and achievement of learning per se, in tandem with feelings of freedom of choice cultivated by education, are linked with satisfaction and hence the accumulation of learning experience would promote SWB (Brighouse, 2006; Novarese \& Rizzello, 2005). In addition, some researchers have suggested highly educated people, as compared to those with lower educational attainment, can acquire self-esteem and self-confidence among others, resulting in higher levels of happiness (Cuñado \& de Gracia 2012; Rodríguez-Pose \& von Berlepsch, 2014).

On the other hand, it has also been empirically revealed education loses (at least partially) its impact on SWB once accounting for the mediation by socio-economic statuses (Oreopoulos \& Salvanes, 2011; Veenhoven, 2010). Furthermore, even negative associations are detected, meaning those with higher levels of educational attainment are more likely than less educated counterparts to report lower levels of satisfaction (Clark \& Oswald, 1996; Nikolaev, 2016; Powdthavee et al., 2015; Shields et al., 2009). This adverse link is often explained as the consequence of high expectations of educated people in terms of their socio-economic statuses. That is, those with high educational attainment generally possess strong aspirations for better occupations and incomes, which are not necessarily realized due to the limited amount of labor market outcomes, and hence the negative impact of not obtaining preferable statuses on happiness could be large among highly educated individuals when indirect influences of education are controlled for (Nikolaev, 2018).

Understanding the direct linkage between education and happiness has thus remained as an unsolved question in social science research. One explanation of the aforementioned variance in evidence is the difference in research targets. In particular, it has been argued that the impact of education on happiness varies depending on such aspects as countries and cohorts (Akaeda, 2019). Indeed, for example, Cuñado (2012) concluded education directly contributed to higher levels of happiness in Spain, while Hu (2015) reported the distinctive contribution of education had declined over time in China. Although these individual cases are valuable to better understand detailed situations in each society, the results of country-specific analyses are not necessarily generalizable. As a result, an overarching conceptual and analytic framework about the link between education and happiness has been lacking for decades.

In this regard, to delineate more generalizable trends that can also be used as the reference in interpreting country-specific findings, it is essential to account for the societal-level factors and their interactions with individual-level education. Specially, one pivotal aspect to be incorporated is the level of educational expansion. As argued by the oft-cited theory of "credential inflation" (Collins, 1979), social scientists have long investigated the link between education and labor market outcomes when considering the extent to which educational opportunity has spread in a given society. Consequently, evidence has suggested that the economic value of educational attainment, as a positional good, decreases as its relative scarcity diminishes in response to societal-level educational expansion (Brown, 2001, 2003; Ortiz \& Rodriguez-Menés, 2016; Tholen, 2017). Meanwhile, previous studies have also revealed the association between education and economic rewards are stable or rather strengthened in conjunction with the proliferation of education in a given society (Bol, 2015), especially when educational expansion progresses in tandem with 
technological advancement that requires highly educated human resources (Acemoglu \& Autor, 2011; Goldin \& Katz, 2008; Lemieux, 2008).

Considering the said nuanced influence of education on labor market outcomes, one may assume the link between education and SWB also varies depending on the degree of societal educational expansion. For example, given that indirect effects of education on life satisfaction are mediated by economic rewards, the overall relationship between education and SWB can diminish in a society where the extent of educational expansion is high according to credential inflation theory (i.e., educational expansion negatively affects the economic value of education, leading to lower levels of satisfaction). In the meantime, the direct effect of education can also decline as more people obtain higher levels of education (i.e., educational expansion) and consequently educated people lose their self-esteem, which has been cultivated by their relatively higher educational attainment in a given society. It is therefore important to pay attention to how the association between education and SWB differs depending on societal educational expansion, which affects the value of education as a positional good. However, while the impact of education on economic rewards has been vigorously examined in consideration of educational expansion, that on happiness has been inadequately explored with the exception of some pioneering research $(\mathrm{Hu}, 2015$; Nikolaev, 2016; Ruiu \& Ruiu, 2019; Salinas-Jiménez et al., 2011).

Herein, educational expansion may influence individuals' happiness not only indirectly via affecting the impact of individuals' educational attainment but also directly as a collective societal condition. Specifically, given that the literature has suggested the growth in access to education operates as an equalizer in a way to mitigate social inequality whilst promoting meritocratic social systems (Veenhoven, 2010), the proliferation of educational opportunities per se might improve SWB by enhancing people's sense that the society where they live is fair, fostering their hope and satisfaction.

In this respect, there is another important societal educational condition to be accounted for: skills diffusion. Focusing on the discrepancy between educational attainment and skills at both the individual and societal levels, Araki (2020) revealed that the level of educational expansion and that of skills diffusion are not necessarily consistent and that these two societal-level variables independently affect the economic value of educational credentials and skills in a nuanced manner. Based on the empirical analysis, he theoretically argued skills diffusion could promote the establishment of meritocratic society where mere credentials are devalued. Should this be the case, the association between individuals' educational attainment and happiness would deteriorate both indirectly (due to the diminishing returns to education) and directly (because of weakened self-esteem that could be generated by being highly educated). Yet, as with the potential function of educational expansion, skills diffusion per se might enhance people's SWB, that is, skills diffusion leads to a more meritocratic and fairer environment through which people may feel higher aspirations and satisfactions. Nevertheless, the literature has largely overlooked the potential impact of skills diffusion on SWB. Put differently, by investigating this association in conjunction with the interaction between individuals' education and societal-level educational expansion, it becomes possible to establish a new conceptual and methodological framework to better explain the function of education in relation to happiness.

Thus, this article explores the link between education and SWB with particular attention to (1) the interaction between individuals' educational attainment and societal educational expansion/skills diffusion; and (2) the association between societal educational expansion/ skills diffusion and individuals' happiness. In so doing, from a positive perspective on the function of education among diverse evidence, the following hypotheses are tested in sequence. 
Hypotheses 1: There is a positive association between education and happiness at the individual level, even after accounting for labor market outcomes.

Hypotheses 2: The association between education and happiness at the individual level is not undermined due to societal-level educational expansion and skills diffusion.

Hypotheses 3: Societal-level educational expansion and skills diffusion are positively associated with individuals' happiness.

\section{Data and Methods}

\subsection{Strategy and Data}

Happiness studies have long detected various determinants of SWB, one at the individual level and the other at the societal level. To precisely analyze the association between education and happiness in consideration of educational expansion and skills diffusion, it is therefore essential to employ multilevel models so that both individual-level and societallevel measures are adjusted for.

Herein, there are primarily two potential analytic strategies: country-specific longitudinal analysis versus cross-country analysis. As reviewed in the previous sections, the former approach is valuable in terms of detailed implications for each research target, but its results are not necessarily generalizable. In contrast, a cross-country study would provide a more general tendency as long as fundamental societal-level variables are properly taken into account, although its findings are not always applicable to each society. While both strategies have advantages and disadvantages, this article employs a cross-country approach as the foundation for detailed country-specific analyses in future research, primarily because of the data availability as described below.

Specifically, the current paper uses the European Social Survey (ESS) as the main database for individual-level variables, in conjunction with country-level data collected by the Organisation for Economic Co-operation and Development (OECD). ESS is a cross-national survey conducted biennially across European countries. Its respondents are selected to ensure representativeness of the population aged 15 and over in each country, and research items range from people's attitudes and beliefs to socio-economic statuses. As ESS provides key individual-level variables including education and SWB, it has been widely used by the literature focused on education and/or happiness (e.g., Cuñado \& de Gracia 2012; Di Stasio et al., 2016). One of the advantages of using ESS is that the dataset is provided alongside several weighting variables, namely analysis weight, post-stratification weight, design weight, and population weight. This means, by using these weights properly, one may conduct a robust comparative analysis addressing biases incurred by sampling errors, non-response errors, and the difference in the population size across countries among others. In this paper, post-stratification weights, which take account of such attributes as age, gender, education, and region, are therefore used for cross-country multilevel analyses as detailed below ${ }^{2}$.

\footnotetext{
${ }^{2}$ As regards the reference year of ESS data, any waves of ESS can technically be utilized to make the nested dataset for cross-country multilevel analyses. To better align with the country-level skills data (i.e., PIAAC) whilst maximizing the number of countries from the same reference year of ESS, the current paper uses ESS Round 6 (2012) with the exception of three countries which did not participate in this wave (i.e.,
} 
For country-level data, three OECD sources are utilized: Education at a Glance; Programme for the International Assessment of Adult Competencies (PIAAC); and OECD. Stat. Education at a Glance is an annual report of the OECD focused on education systems across member and some non-member countries and economies, reporting national statistics including the percentage of the population who have attained tertiary education, which is used as a measure of educational expansion in this article. PIAAC is an international survey of cognitive skills and socio-economic statuses of adults aged 16-65 who are selected in a way to represent the population. More than 40 countries/economics have participated in this survey in different years ranging from 2011-2012 (Round 1) through 2014-2015 (Round 2) to 2017 (Round 3), and the first round of the second cycle is currently planned. The main fields of assessments are literacy and numeracy, both of which are quantified by $0-500$ raw scores. These scores can be further converted into six proficiency levels: Below Level 1 (0-175); Level 1 (176-225); Level 2 (226-275); Level 3 (276-325); Level 4 (326-375); and Level 5 (376-500). Among these six levels, the OECD defines Level 4 and Level 5 as high skills based on test theory, and Araki (2020) used the share of respondents with high skills (i.e., Level 4 or 5 in PIAAC) as the measure of skills diffusion in analyzing economic returns to education. Following this strategy, the current paper also employs this indicator to investigate the link between education and happiness. Finally, OECD.Stat is the online database of country-level key indicators concerning multidimensional wellbeing such as macroeconomy, income inequality, life expectancy, safety, and civic engagement across OECD countries and beyond ${ }^{3}$. As detailed below, several measures are derived from this source to re-examine the robustness of the main analysis result.

\subsection{Variables}

In terms of specific variables, the outcome is the answer to the question about life satisfaction assessed by the Cantril Ladder, with 0 being the worst and 10 being the best, given that the vast literature has proved the high validity and robustness of this measure (Cuñado \& de Gracia 2012; Frey \& Stutzer, 2002; Helliwell et al., 2020; Ruiu \& Ruiu, 2019). Meanwhile, as argued earlier, there have been discussions on the importance of paying attention to the distinction across different measures of SWB. This article therefore primarily uses the level of life satisfaction in the main manuscript, and another variable concerning happiness (i.e., the answer to the question "Taking all things together, how happy would you say you are?" from 0 being extremely unhappy to 10 being extremely happy) is further used as a robustness check. The analysis result using this happiness indicator is described in "Appendix in Table 6".

As regards predictor variables, educational attainment is quantified by whether respondents possess tertiary education degrees including short-cycle ones (i.e., tertiary graduates are assigned 1 and 0 otherwise). Herein, it is important to note that previous research has confirmed the heterogeneous returns to education across fields of study as well as prestige of higher education institutions among others (Bills, 2016; Bol et al., 2019; Borgen \& Mastekaasa, 2018; Ortiz \& Rodriguez-Menés, 2016; Posselt \& Grodsky, 2017; Di Stasio, 2017;

\section{Footnote 2 (continued)}

Austria in 2010, Greece in 2010, and Turkey in 2008). For more details of ESS, see the website (https:// www.europeansocialsurvey.org/). [Accessed: 20 January 2021].

${ }^{3}$ For more details of OECD.Stat, see the website (https://stats.oecd.org/). [Accessed: 20 January 2021]. 
Sullivan et al., 2018; Tholen, 2017). This means, nuanced associations between education and happiness may be detectable once the variation within tertiary degrees are taken into account. Furthermore, the literature has suggested socio-economic rewards differ depending not only on educational attainment but also on skills levels of individuals (Araki, 2020; Hanushek et al., 2015). One potential approach is therefore to incorporate various types of educational credentials and skills, analyzing (the heterogeneity in) their impact on SWB. However, the primary aim of this article is not to elucidate detailed relationships between happiness and educational qualifications that individuals possess, but rather to capture the general trend of the link between education and SWB with close attention to the impact of societal-level educational expansion and skills diffusion as well as their interactions with individual-level education. To this end, incorporating different types of credentials and skills at the individual level would possibly obscure the main finding/argument. In addition, as a matter of fact, ESS and other international surveys do not collect skills data, whereas PIAAC does not directly assess SWB. Individuals' education is thus primarily measured by the tertiary degree dummy in this article to establish the foundation for future research. Nonetheless, ESS permits an analysis incorporating different levels of educational attainment and indeed some prior studies have used them separately (e.g., Cuñado $\&$ de Gracia, 2012). Considering the potential bias due to using the only one dichotomized threshold (i.e., tertiary education), the present paper therefore conducts an additional analysis including two more dummies for educational attainment (i.e., upper secondary and post-secondary non-tertiary), and its result is shown in "Appendix in Table 13".

In terms of other predictors, the current paper uses key variables that have proved to be significant determinants of SWB rather than relying on "usual suspects" (Bartram, 2021). This includes age and age squared, gender, marital status, the presence of child(ren), selfreported health status, main activity (occupations), and income (e.g., Aassve et al., 2012; Akaeda, 2019; Bartram, 2021; D'Ambrosio et al., 2020; Helliwell et al., 2020; Perelli-Harris et al., 2019; Steptoe et al., 2015; van der Meer, 2014). Indeed, Cuñado and de Gracia (2012) detected a substantial association between happiness and these attributes in their empirical analysis using the ESS data. Furthermore, given that a number of studies have revealed trust and social connections operate as important predictors of happiness (e.g., Edling et al., 2014; Haller \& Hadler, 2006; Helliwell et al., 2020; Lim \& Putnam, 2010; Rodríguez-Pose \& von Berlepsch, 2014), the current paper also uses questions about the frequency of volunteer activity and the extent to which respondents feel people can be trusted.

Main country-level indicators are the level of educational expansion and that of skills diffusion. In accordance with the literature (e.g., Araki, 2020), as mentioned above, educational expansion refers to the share of people who have attained tertiary education, whereas skills diffusion is measured by the mean of the percentage of PIAAC participants with literacy proficiency level 4 or 5 and that with numeracy proficiency level 4 or 5 . Herein, a significant limitation of using these country-level variables is that they do not reflect timeseries variations in each society due to the data availability (i.e., PIAAC has been administered only once for each country except for the United States), despite the original concept of educational expansion and skills diffusion, both of which imply longitudinal changes. However, the cross-country difference in the said measures in a multilevel model can be taken as a quasi-indicator that suggests the extent to which each society has relatively progressed educational expansion and skills diffusion.

Meanwhile, one alternative is the utilization of cross-cohort differences within countries and their variations across countries. That is, as demonstrated by Araki (2020) in his crosscountry multilevel analyses using the PIAAC data, the difference in the percentage of the 
population with tertiary degrees and high skills, respectively, between older versus younger cohorts can be used as a quasi-measure of some changes in each society, albeit not directly capturing the longitudinal transformation. In addition to the status quo measured by the share of tertiary graduates and highly skilled people, this article therefore incorporates this cross-cohort design focused on the difference between the older group (i.e., ages 55-65) and the younger group (i.e., ages 25-34). More details about analytic models are explained in the next section.

While the focus of this article is on the aforementioned educational variables (including their interactions with individuals' educational attainment), several societal conditions are also incorporated to re-examine the robustness of the main analysis results (see "Appendix in Table 10"). Specifically, according to findings of recent research focused on the difference in happiness across country/city (see Helliwell et al., 2020; Kelley \& Evans, 2017), the following measures are employed: GDP per capita (purchasing power parity); Gini index (disposable income, post taxes and transfers); Dwellings without basic facilities; Long-term unemployment; Quality of support network; Civic engagement (i.e., voter turnout); Life expectancy; Air pollution; and Homicide rate ${ }^{4}$. It is important to note that some of country-level data were collected after individual-level ESS data, meaning that the time order of the outcome variable and controls is reversed. Nevertheless, in addition to the fact that the utilization of these societal conditions is not for causal inference but for robustness checks, the relative position of country-level indicators across country (e.g., the ranking of GDP per capita) does not change dramatically within a few years and therefore a slight inconsistency of timing of data collection, at least in this analysis, is not necessarily a serious problem. Indeed, another robustness check, in which one country (i.e., Turkey) whose individual-level data were collected several years prior to country-level data is excluded, demonstrates the consistent result with the main analysis including Turkey (see "Appendix in Table 9").

Target countries, the number of respondents, and the average life satisfaction level in each country are shown in Table 1, while Table 2 summarizes descriptive statistics of variables. As indicated in these tables, all individuals aged 15 and over in the ESS dataset are included in the analysis as long as they have valid data for all measures. One may assume that many respondents of the young cohort, say those aged from 15 to 29, have not completed their education and therefore the estimation could be biased. The present paper thus conducts analyses using two datasets: one including all cohorts (explained in the main manuscript) and the other limited to respondents aged 30 and over (shown in "Appendix in Table 8"). Note that the main findings and implications are consistent between two models.

\subsection{Analytic Models}

By nesting the aforementioned individual-level data (from ESS) and societal-level data (from Education at a Glance, PIAAC, and OECD.Stat), multilevel linear regression

\footnotetext{
${ }^{4}$ Dwellings without basic facilities, long-term unemployment, quality of support network, voter turnout, life expectancy, air pollution, and homicide rate are measured by the percentage of the population living in a dwelling without basic facilities, the percentage of the labor force who has been unemployed for one year or more, the percentage of respondents of an international survey who positively answered the question "If you were in trouble, do you have relatives or friends you can count on to help you whenever you need them, or not?", the percentage of the population registered to vote who cast a ballot during an election, the number of years on average people could expect to live, the average of annual concentrations of PM2.5 in the air, and the number of deaths due to assault per 100,000 population, respectively.
} 
Table 1 Target countries and the number of respondents

\begin{tabular}{|c|c|c|c|c|}
\hline \multirow[t]{2}{*}{ Country (Code) } & \multirow[t]{2}{*}{ ESS } & \multirow[t]{2}{*}{ Respondents } & \multicolumn{2}{|c|}{$\begin{array}{l}\text { Life satisfac- } \\
\text { tion }(0-10)\end{array}$} \\
\hline & & & Mean & S.D \\
\hline Austria (AT) & 2010 & 2,161 & 7.41 & 1.95 \\
\hline Belgium (BE) & 2012 & 1,861 & 7.44 & 1.76 \\
\hline Czech republic (CZ) & 2012 & 1,844 & 6.55 & 2.17 \\
\hline Denmark (DK) & 2012 & 1,620 & 8.57 & 1.50 \\
\hline Estonia (EE) & 2012 & 2,353 & 6.18 & 2.37 \\
\hline Finland (FI) & 2012 & 2,176 & 8.11 & 1.40 \\
\hline France (FR) & 2012 & 1,960 & 6.40 & 2.46 \\
\hline Germany (DE) & 2012 & 2,910 & 7.48 & 2.05 \\
\hline Greece (GR) & 2010 & 2,694 & 5.65 & 2.33 \\
\hline Hungary (HU) & 2012 & 1,964 & 5.59 & 2.42 \\
\hline Ireland (IE) & 2012 & 2,575 & 6.71 & 2.24 \\
\hline Israel (IL) & 2012 & 2,346 & 7.52 & 2.09 \\
\hline Italy (IT) & 2012 & 887 & 6.69 & 2.35 \\
\hline Lithuania (LT) & 2012 & 2,041 & 5.83 & 2.21 \\
\hline Netherlands (NL) & 2012 & 1,824 & 7.76 & 1.56 \\
\hline Norway (NO) & 2012 & 1,615 & 8.14 & 1.57 \\
\hline Poland (PL) & 2012 & 1,863 & 7.09 & 2.28 \\
\hline Russian federation (RU) & 2012 & 2,365 & 5.80 & 2.32 \\
\hline Slovak republic (SK) & 2012 & 1,792 & 6.55 & 2.24 \\
\hline Slovenia (SI) & 2012 & 1,234 & 6.98 & 2.20 \\
\hline Spain (ES) & 2012 & 1,854 & 6.89 & 2.33 \\
\hline Sweden (SE) & 2012 & 1,805 & 7.87 & 1.70 \\
\hline Turkey (TR) & 2008 & 2,282 & 5.52 & 2.87 \\
\hline United Kingdom (GB) & 2012 & 2,221 & 7.28 & 2.07 \\
\hline Total & & 48,247 & 6.87 & 2.31 \\
\hline
\end{tabular}

"ESS" means the year in which the European Social Survey data are derived for each country, whereas S.D. indicates the standard deviation. To better align individual-level data with country-level data, the reference year of ESS is 2012 for all the target countries except for Austria (2010), Greece (2010), and Turkey (2008) as these three countries did not participate in the 2012 survey. The number of respondents shown in this table is limited to valid cases for the following analyses. In all countries, the minimum and the maximum values of life satisfaction are 0 and 10 , respectively.

analyses are conducted. Given the nature of the outcome variable (0-10 life satisfaction score), multilevel ordered logistic regression is another option. However, prior research has revealed there is little difference between linear models and ordered logit ones in the analysis of SWB (Ferrer-i-Carbonell \& Frijters, 2004; Nikolaev, 2016). Indeed, as both approaches demonstrate the consistent findings in this research as well, the linear model is used in the main manuscript for brevity and the logistic regression is shown in "Appendix 
Table 2 Descriptive statistics

\begin{tabular}{|c|c|c|c|c|}
\hline Variables & Mean & S.D & Min. & Max. \\
\hline \multicolumn{5}{|l|}{ Individual level } \\
\hline Life satisfaction ( $0-10$ scale) & 6.87 & 2.31 & 0.00 & 10.00 \\
\hline Tertiary education (dummy) & 0.21 & 0.41 & 0.00 & 1.00 \\
\hline Age & 47.73 & 18.50 & 15.00 & 105.00 \\
\hline Age squared & 2620.30 & 1844.70 & 225.00 & $11,025.00$ \\
\hline Gender (men dummy) & 0.46 & 0.50 & 0.00 & 1.00 \\
\hline Legally married (dummy) & 0.47 & 0.50 & 0.00 & 1.00 \\
\hline Legally registered civil union (dummy) & 0.01 & 0.09 & 0.00 & 1.00 \\
\hline Legally separated (dummy) & 0.01 & 0.07 & 0.00 & 1.00 \\
\hline Legally divorced/dissolved (dummy) & 0.09 & 0.29 & 0.00 & 1.00 \\
\hline Widowed/partner died (dummy) & 0.09 & 0.28 & 0.00 & 1.00 \\
\hline Living with children (dummy) & 0.37 & 0.48 & 0.00 & 1.00 \\
\hline Trust (0-10 scale) & 4.99 & 2.47 & 0.00 & 10.00 \\
\hline Religion or denomination (dummy) & 0.61 & 0.49 & 0.00 & 1.00 \\
\hline Volunteer: at least once a week (dummy) & 0.06 & 0.24 & 0.00 & 1.00 \\
\hline Volunteer: at least once a month (dummy) & 0.06 & 0.24 & 0.00 & 1.00 \\
\hline $\begin{array}{l}\text { Volunteer: at least once every three months } \\
\text { (dummy) }\end{array}$ & 0.04 & 0.20 & 0.00 & 1.00 \\
\hline Volunteer: at least once every six months (dummy) & 0.05 & 0.22 & 0.00 & 1.00 \\
\hline Volunteer: less often (dummy) & 0.11 & 0.31 & 0.00 & 1.00 \\
\hline Health: very good (dummy) & 0.24 & 0.43 & 0.00 & 1.00 \\
\hline Health: good (dummy) & 0.41 & 0.49 & 0.00 & 1.00 \\
\hline Health: fair (dummy) & 0.27 & 0.44 & 0.00 & 1.00 \\
\hline Health: bad (dummy) & 0.07 & 0.25 & 0.00 & 1.00 \\
\hline Main activity: paid work (dummy) & 0.07 & 0.26 & 0.00 & 1.00 \\
\hline Main activity: education (dummy) & 0.01 & 0.11 & 0.00 & 1.00 \\
\hline $\begin{array}{l}\text { Main activity: unemployed/looking for a job } \\
\text { (dummy) }\end{array}$ & 0.00 & 0.07 & 0.00 & 1.00 \\
\hline $\begin{array}{l}\text { Main activity: unemployed/not looking for a job } \\
\text { (dummy) }\end{array}$ & 0.00 & 0.04 & 0.00 & 1.00 \\
\hline Main activity: permanently sick/disabled (dummy) & 0.00 & 0.07 & 0.00 & 1.00 \\
\hline Main activity: retired (dummy) & 0.03 & 0.16 & 0.00 & 1.00 \\
\hline Main activity: community/military service (dummy) & 0.00 & 0.01 & 0.00 & 1.00 \\
\hline $\begin{array}{l}\text { Main activity: housework/looking after others } \\
\text { (dummy) }\end{array}$ & 0.02 & 0.14 & 0.00 & 1.00 \\
\hline Income: comfortable (dummy) & 0.25 & 0.43 & 0.00 & 1.00 \\
\hline Income: coping (dummy) & 0.45 & 0.50 & 0.00 & 1.00 \\
\hline Income: difficult (dummy) & 0.21 & 0.41 & 0.00 & 1.00 \\
\hline \multicolumn{5}{|l|}{ Country level } \\
\hline Educational expansion & 29.873 & 9.318 & 13.118 & 50.371 \\
\hline Skills diffusion & 10.429 & 4.535 & 0.993 & 20.812 \\
\hline Cross-cohort difference in educational expansion & 13.531 & 6.789 & -2.023 & 28.166 \\
\hline Cross-cohort difference in skills diffusion & 10.267 & 5.840 & 0.840 & 28.076 \\
\hline GDP per capita & $36,810.220$ & $10,752.254$ & $22,204.865$ & $66,956.286$ \\
\hline Gini index & 0.306 & 0.043 & 0.252 & 0.390 \\
\hline
\end{tabular}


Table 2 (continued)

\begin{tabular}{lrrrr}
\hline Variables & \multicolumn{1}{c}{ Mean } & S.D & Min. & Max. \\
\hline Dwellings without basic facilities & 2.546 & 3.832 & 0.000 & 13.600 \\
Long-term unemployment & 3.763 & 2.629 & 0.380 & 8.990 \\
Quality of support network & 90.042 & 4.895 & 73.000 & 96.000 \\
Voter turnout & 70.250 & 11.417 & 47.000 & 89.000 \\
Life expectancy & 79.192 & 3.195 & 69.800 & 82.700 \\
Air pollution & 19.458 & 7.773 & 9.000 & 37.000 \\
Homicide rate & 1.921 & 2.019 & 0.600 & 10.200 \\
Observations & Individuals $=48,247$ Countries $=24$ &
\end{tabular}

The reference year of "Educational Expansion" is 2012 as with ESS for most countries. "Skills Diffusion" refers to years in which each country participated in PIAAC, ranging from 2011-2012 (Round 1) through 2014-2015 (Round 2) to 2017 (Round 3). The reference years of "GDP per capita" and "Gini index" are both 2013 except Russia for which "Gini index" refers to 2011 due to data availability, whereas other country-level variables are derived from the Better Life Index 2013 in OECD.Stat.

Source: ESS 2012, OECD (2014a, 2014b, 2019), OECD.Stat

in Table 7"5. Specifically, in Model 1, only individual-level variables without labor market outcomes (i.e., occupations and income) are used in relation to Hypothesis 1 (i.e., the link between education and happiness at the individual level) as follows.

$$
\begin{aligned}
Y_{i j}= & b_{0 j}+b_{1} E_{i j}+b_{2} A_{i j}+b_{3} A_{i j}^{2}+b_{4} M_{i j}+b_{5} L M_{i j}+b_{6} C U_{i j}+b_{7} L S_{i j} \\
& +b_{8} L D_{i j}+b_{9} W_{i j}+b_{10} C_{i j}+b_{11} T_{i j}+b_{12} R_{i j}+b_{13} V w_{i j} \\
& +b_{14} V m_{i j}+b_{15} V q_{i j}+b_{16} V b_{i j}+b_{17} V o_{i j}+b_{18} H v_{i j} \\
& +b_{19} H g_{i j}+b_{20} H f_{i j}+b_{21} H b_{i j}+\varepsilon_{i j}
\end{aligned}
$$

where $i=$ level one (individual), $j=$ level two (country), $Y_{\mathrm{ij}}=$ the level of life satisfaction for individual $\mathrm{i}$ in country $\mathrm{j}, b_{\mathrm{n}}=$ coefficient of individual-level predictor variables, $E_{\mathrm{ij}}=$ educational attainment (tertiary degree dummy), $A_{\mathrm{ij}}=$ age, $A_{\mathrm{ij}}^{2}=$ age squared, $M_{\mathrm{ij}}=$ men dummy, $L M_{\mathrm{ij}}=$ legally married dummy, $C U_{\mathrm{ij}}=$ legally registered civil union dummy, $L S_{\mathrm{ij}}=$ legally separated dummy, $L D_{\mathrm{ij}}=$ legally divorced/civil union dissolved dummy, $W_{i j}=$ widowed/ civil partner died dummy, $C_{i j}=$ living with children dummy, $T_{i j}=$ trust score (from 0 [You can't be too careful] to 10 [Most people can be trusted]), $R_{i j}=$ religion dummy (belonging to any particular religion or denomination), $V w_{i j}=$ voluntary or charitable activity dummy: at least once a week, $V m_{i j}=$ voluntary or charitable activity dummy: at least once a month, $V q_{i j}=$ voluntary or charitable activity dummy: at least once every three months, $V b_{i j}=$ voluntary or charitable activity dummy: at least once every six months, $V o_{i j}=$ voluntary or charitable activity dummy: less often (with "never" as the reference), $H v=$ health status: very good, $H g=$ health status: good, $H f=$ health status: fair, $H b=$ health status: bad (with

\footnotetext{
${ }^{5}$ One must recognize that coefficients of predictors (including interaction terms) in nonlinear models, unlike linear models, should not be interpreted as substantive values (i.e., their effects should be carefully examined with attention to the cross derivative/difference/marginal effects) (Ai \& Norton 2003; Breen et al., 2018). Yet, "Appendix in Table 7" simply shows the coefficients and standard errors as with other models because the logistic regression adopted here is merely to test the robustness of linear models and, importantly, the results of linear and nonlinear models are consistent.
} 
"very bad" as the reference), and $\varepsilon_{\mathrm{ij}}=$ residual for individual $i$ in country $j$. Coefficient of educational attainment $\left(b_{1}\right)$ indicates the overall association between education and happiness including the ones mediated by labor market outcomes.

Model 2 adds variables concerning main activity (occupations) and income to Model 1 to further examine Hypothesis 1: whether the significant link between education and happiness (if any) is still confirmed after accounting for labor market outcomes. One potential approach here is to include these two economic measures separately to identify which status is more significant as a mediator of the association between education and happiness. Although this strategy provides insights into the nuanced structure of education, economic rewards, and happiness, the primary focus of this research is on (1) how the function of individuals' educational attainment varies depending on societal-level educational conditions and (2) how such societal-level educational conditions are directly associated with individuals' SWB, rather than the detailed path from education to happiness at the individual level. Thus, while the results of analyses incorporating occupations and income separately are shown in "Appendix in Table 11" for reference, these two variables are concurrently included in the main manuscript as follows. As with Model $1, b_{1}$ of the equation is primarily focused on.

$$
\begin{aligned}
Y_{i j}= & b_{0 j}+b_{1} E_{i j}+b_{2} A_{i j}+b_{3} A_{i j}^{2}+b_{4} M_{i j}+b_{5} L M_{i j}+b_{6} C U_{i j}+b_{7} L S_{i j} \\
& +b_{8} L D_{i j}+b_{9} W_{i j}+b_{10} C_{i j}+b_{11} T_{i j}+b_{12} R_{i j}+b_{13} V w_{i j} \\
& +b_{14} V m_{i j}+b_{15} V q_{i j}+b_{16} V b_{i j}+b_{17} V o_{i j}+b_{18} H v_{i j} \\
& +b_{19} H g_{i j}+b_{20} H f_{i j}+b_{21} H b_{i j}+b_{22} M w_{i j}+b_{23} M e_{i j} \\
& +b_{24} M j_{i j}+b_{25} M u_{i j}+b_{26} M s_{i j}+b_{27} M r_{i j}+b_{28} M c_{i j} \\
& +b_{29} M h_{i j}+b_{30} I c_{i j}+b_{31} I o_{i j}+b_{32} I d_{i j}+\varepsilon_{i j}
\end{aligned}
$$

where $M w=$ main activity: paid work, $M e=$ main activity: education, $M j=$ main activity: unemployed and actively looking for a job, $M u=$ main activity: unemployed and not actively looking for a job, $M s=$ main activity: permanently sick or disabled, $M r=$ main activity: retired, $M c=$ main activity: community or military service, $M h=$ main activity: housework/looking after children/other persons (with "others" as the reference), $I c=$ income: comfortable, $I o=$ income: coping, and $I d=$ income: difficult (with "very difficult" as the reference).

In Model 3, the degree of educational expansion (EE), that of skills diffusion $(S D)$ and their interactions with individual-level education (i.e., $E^{*} E E$ and $E^{*} S D$, respectively) are added to Model 1 to partially test Hypothesis 2 (i.e., how the overall link between education and happiness changes due to the extent of educational expansion and skills diffusion). Given the importance of employing a random slope for the lower-level variables involved in cross-level interactions in multilevel analyses (Heisig \& Schaeffer, 2019), Model 3 incorporates a random effect of individual-level education $(E)$ in conjunction with a random intercept as follows.

$$
b_{0 j}(\text { in equation } 1)=\gamma_{00}+\gamma_{01} E E_{j}+\gamma_{02} S D_{j}+u_{0 j}
$$

And

$$
b_{1}(\text { in equation } 1)=\gamma_{10}+u_{1 j}
$$

where $\gamma_{00}=$ average intercept, $\gamma_{0 n}=$ coefficient of country-level predictor variables, $u_{0 j}=$ country $(j)$ dependent deviation of the intercept, $\gamma_{10}=$ average coefficient of individual-level education $(E)$, and $u_{1 j}=$ country dependent deviation of the education slope. Substituting 
Eqs. (3a) and (3b) into Eq. (1) and denoting $b_{\mathrm{n}}$ by $\gamma_{\mathrm{n} 0}$, an equation for Model 3 can be described as follows.

$$
\begin{aligned}
Y_{i j}= & \gamma_{00}+\left(\gamma_{10}+u_{1 j}\right) E_{i j}+\gamma_{20} A_{i j}+\gamma_{30} A_{i j}^{2}+\gamma_{40} M_{i j}+\gamma_{50} L M_{i j} \\
& +\gamma_{60} C U_{i j}+\gamma_{70} L S_{i j}+\gamma_{80} L D_{i j}+\gamma_{90} W_{i j}+\gamma_{100} C_{i j} \\
& +\gamma_{110} T_{i j}+\gamma_{120} R_{i j}+\gamma_{130} V w_{i j}+\gamma_{140} V m_{i j}+\gamma_{150} V q_{i j} \\
& +\gamma_{160} V b_{i j}+\gamma_{170} V o_{i j}+\gamma_{180} H v_{i j}+\gamma_{190} H g_{i j}+\gamma_{200} H f_{i j} \\
& +\gamma_{210} H b_{i j}+\gamma_{01} E E_{j}+\gamma_{02} S D_{j}+\gamma_{11} E_{i j} E E_{j}+\gamma_{12} E_{i j} S D_{j} \\
& +u_{0 j}+\varepsilon_{i j} \\
= & \gamma_{00}+\gamma_{10} E_{i j}+\gamma_{20} A_{i j}+\gamma_{30} A_{i j}^{2}+\gamma_{40} M_{i j}+\gamma_{50} L M_{i j}+\gamma_{60} C U_{i j} \\
& +\gamma_{70} L S_{i j}+\gamma_{80} L D_{i j}+\gamma_{90} W_{i j}+\gamma_{100} C_{i j}+\gamma_{110} T_{i j} \\
& +\gamma_{120} R_{i j}+\gamma_{130} V w_{i j}+\gamma_{140} V m_{i j}+\gamma_{150} V q_{i j}+\gamma_{160} V b_{i j} \\
& +\gamma_{170} V o_{i j}+\gamma_{180} H v_{i j}+\gamma_{190} H g_{i j}+\gamma_{200} H f_{i j}+\gamma_{210} H b_{i j} \\
& +\gamma_{01} E E_{j}+\gamma_{02} S D_{j}+\gamma_{11} E_{i j} E E_{j}+\gamma_{12} E_{i j} S D_{j}+u_{0 j} \\
& +u_{1 j} E_{i j}+\varepsilon_{i j}
\end{aligned}
$$

where $\gamma_{11}$ and $\gamma_{12}$ explain how the association between education and happiness (including the mediation by labor market outcomes) differs depending on the level of educational expansion and skills diffusion. Herein, it is also meaningful to incorporate $E E$ and $S D$ separately to examine the relationship between individual-level education and societal-level conditions in a more detailed manner. The results of analyses adding these two indicators separately are thus shown in "Appendix in Table 12" for reference.

Taking the same step as Model 3, Model 4 adds EE, SD, and their interactions with individual-level education to Model 2 to further test Hypothesis 2 (i.e., heterogeneity in the linkage between education and life satisfaction net of labor market outcomes when considering educational expansion and skills diffusion). By shedding light on the parameters for $E E\left(\gamma_{01}\right)$ and $S D\left(\gamma_{02}\right)$ in this model, Hypothesis 3 (i.e., the relationship between societal educational expansion/skills diffusion and individual-level happiness) is also examined.

$$
\begin{aligned}
Y_{i j}= & \gamma_{00}+\gamma_{10} E_{i j}+\gamma_{20} A_{i j}+\gamma_{30} A_{i j}^{2}+\gamma_{40} M_{i j}+\gamma_{50} L M_{i j}+\gamma_{60} C U_{i j} \\
& +\gamma_{70} L S_{i j}+\gamma_{80} L D_{i j}+\gamma_{90} W_{i j}+\gamma_{100} C_{i j}+\gamma_{110} T_{i j} \\
& +\gamma_{120} R_{i j}+\gamma_{130} V w_{i j}+\gamma_{140} V m_{i j}+\gamma_{150} V q_{i j}+\gamma_{160} V b_{i j} \\
& +\gamma_{170} V o_{i j}+\gamma_{180} H v_{i j}+\gamma_{190} H g_{i j}+\gamma_{200} H f_{i j}+\gamma_{210} H b_{i j} \\
& +\gamma_{220} M w_{i j}+\gamma_{230} M e_{i j}+\gamma_{240} M j_{i j}+\gamma_{250} M u_{i j} \\
& +\gamma_{260} M s_{i j}+\gamma_{270} M r_{i j}+\gamma_{280} M c_{i j}+\gamma_{290} M h_{i j}+\gamma_{300} I c_{i j} \\
& +\gamma_{310} I o_{i j}+\gamma_{320} I d_{i j}+\gamma_{01} E E_{j}+\gamma_{02} S D_{j}+\gamma_{11} E_{i j} E E_{j} \\
& +\gamma_{12} E_{i j} S D_{j}+u_{0 j}+u_{1 j} E_{i j}+\varepsilon_{i j}
\end{aligned}
$$

Finally, as argued in the previous section, $E E$ and $S D$ in Model 3 and Model 4 (i.e., the status quo of the relative degree of educational expansion and skills diffusion) are replaced with the cross-cohort difference in these measures in each country (i.e., DifEE and DifSD). 
While these analyses are described as Model 5 and Model 6 alongside other models, their results that follow are largely consistent with Models 3 and 4.

As mentioned, a number of robustness checks are conducted to verify the analysis results and implications as follows: "Appendix in Table 6" using another outcome variable (i.e., the happiness scale instead of life satisfaction); "Appendix in Table 7" employing the ordered logistic regression instead of the linear model; "Appendix in Table 8" excluding respondents aged below 30; "Appendix in Table 9" excluding Turkey where individuallevel data were collected relatively earlier; "Appendix in Table 10" adding other countrylevel variables; "Appendix in Table 11" incorporating occupations and income separately; "Appendix in Table 12" adding EE and $S D$ (and their interactions with individuals' educational attainment) separately; and "Appendix in Table 13" incorporating several levels of educational attainment in addition to tertiary degrees. Given that a) the analysis results are consistent between Models 3/4 with EE/SD and Models 5/6 with DifEE/DifSD; and b) the former models fit slightly better than the latter ones (i.e., AIC is lower as shown in Tables 4 and 5), Models 3/4 are used as the base for robustness checks ${ }^{6}$.

\section{Results}

Table 3 illustrates the analysis results of Model 1 and Model 2. In Model 1, which focuses on the overall association between education and happiness including the mediation by occupations and income (i.e., these two dimensions are not controlled for), the tertiary education dummy shows a positive sign at the $0.1 \%$ significance level $\left(b_{1}=0.192\right)$. This means, as indicated in Hypothesis 1, tertiary graduates are more likely than less educated counterparts to enjoy higher levels of life satisfaction, corroborating previous research that has detected the positive effect of education on SWB. It is also worthy of note that the association between other individual-level predictors and the outcome variable is consistent with prior studies, including the negative coefficients of age and separated status in conjunction with the positive signs of squared age, legally married/registered civil union statuses, trust, and voluntary activities.

However, once the said labor market outcomes are accounted for in Model 2 that fits better than Model 1 (i.e., AICs of Model 1 and Model 2 are 203,159.3 and 199,534.8, respectively), the significant coefficient of tertiary education is no longer confirmed despite its sufficiently small standard error (i.e., 0.041). Meanwhile, the unemployed status (looking for job opportunities) and income levels demonstrate substantially negative and positive signs, respectively. Herein, according to the analyses incorporating occupations and income separately (see "Appendix in Table 11"), the positive coefficient of education is still significant at the $1 \%$ level in a model where only occupations are controlled for. Yet, this is not the case for the one that includes income levels as predictors without occupations,

\footnotetext{
${ }^{6}$ More analyses are possible by multiplying these robustness checks (e.g., only occupations and $E E$ are included without income and $S D$; the happiness scale is used as the outcome in an ordered logit model; and controls regarding societal conditions such as GDP and safety are incorporated in an analysis only for respondents in their $30 \mathrm{~s}$ and over). The results of these models are all consistent with the one described in the main manuscript and hence they are not employed in the current paper given the space constraints.
} 
Table 3 Multilevel linear regression of life satisfaction

\begin{tabular}{|c|c|c|c|c|}
\hline \multirow[t]{2}{*}{ Predictor variables } & \multicolumn{2}{|l|}{ Model 1} & \multicolumn{2}{|l|}{ Model 2} \\
\hline & B & S.E. & B & S.E. \\
\hline Intercept & $5.001 * * *$ & 0.213 & $4.003 * * *$ & 0.194 \\
\hline \multicolumn{5}{|l|}{ Level one (individual) } \\
\hline Tertiary education & $0.192 * *$ & 0.061 & -0.033 & 0.041 \\
\hline Age & $-0.080 * * *$ & 0.007 & $-0.069 * * *$ & 0.006 \\
\hline Age squared & $0.001 * * *$ & 0.000 & $0.001 * * *$ & 0.000 \\
\hline Men & $-0.098 * *$ & 0.035 & $-0.136^{* * *}$ & 0.032 \\
\hline \multicolumn{5}{|l|}{ Marital status (reference $=$ others $)$} \\
\hline Legally married & $0.499 * * *$ & 0.045 & $0.386^{* * * *}$ & 0.044 \\
\hline Legally registered civil union & $0.436 * * *$ & 0.097 & $0.368 * * *$ & 0.103 \\
\hline Legally separated & $-0.473^{* * *}$ & 0.089 & $-0.324 * *$ & 0.098 \\
\hline Legally divorced/dissolved & $-0.119 *$ & 0.055 & -0.004 & 0.052 \\
\hline Widowed/partner died & -0.023 & 0.093 & 0.040 & 0.089 \\
\hline Living with children & -0.068 & 0.036 & 0.019 & 0.030 \\
\hline Trust & $0.163 * * *$ & 0.007 & $0.136^{* * * *}$ & 0.007 \\
\hline Religion or denomination & $0.094^{*}$ & 0.043 & $0.112^{* *}$ & 0.034 \\
\hline \multicolumn{5}{|c|}{ Voluntary/charitable activity (reference $=$ never) } \\
\hline At least once a week & $0.286 * * *$ & 0.051 & $0.250 * * *$ & 0.048 \\
\hline At least once a month & $0.229 * * *$ & 0.048 & $0.175 * * *$ & 0.043 \\
\hline At least once every three months & $0.188 * * *$ & 0.050 & $0.115^{*}$ & 0.046 \\
\hline At least once every six months & 0.143 & 0.078 & 0.080 & 0.073 \\
\hline Less often & 0.048 & 0.044 & 0.019 & 0.039 \\
\hline \multicolumn{5}{|l|}{ Health status (reference $=$ very bad) } \\
\hline Very good & $3.033 * * *$ & 0.141 & $2.505 * * *$ & 0.139 \\
\hline Good & $2.632 * * *$ & 0.120 & $2.162 * * *$ & 0.121 \\
\hline Fair & $1.952 * * *$ & 0.130 & $1.619 * * *$ & 0.136 \\
\hline $\mathrm{Bad}$ & $1.069 * * *$ & 0.146 & $0.961 * * *$ & 0.146 \\
\hline \multicolumn{5}{|l|}{ Main activity (reference $=$ others) } \\
\hline Paid work & & & -0.074 & 0.040 \\
\hline Education & & & -0.040 & 0.078 \\
\hline Unemployed/looking for a job & & & $-0.529 * *$ & 0.181 \\
\hline Unemployed/not looking for a job & & & -0.666 & 0.421 \\
\hline Permanently sick/disabled & & & -0.145 & 0.138 \\
\hline Retired & & & -0.003 & 0.050 \\
\hline Community/military service & & & -0.976 & 0.596 \\
\hline Housework/looking after others & & & -0.069 & 0.093 \\
\hline \multicolumn{5}{|l|}{ Income (reference $=$ very difficult $)$} \\
\hline Comfortable & & & $2.093 * * *$ & 0.106 \\
\hline Coping & & & $1.616 * * *$ & 0.086 \\
\hline Difficult & & & $0.820 * * *$ & 0.066 \\
\hline \multicolumn{5}{|l|}{ Variance (random effect) } \\
\hline Covariance structure (intercept) & 0.406 & & 0.222 & \\
\hline \multicolumn{5}{|l|}{ Model fit } \\
\hline AIC & $203,159.3$ & & $199,534.8$ & \\
\hline
\end{tabular}

Data are weighted using post-stratification weights.

$* * * p<0.001, * * p<0.01, * p<0.05$ [two tailed] [N: Individual $=48,247$, Country $=24$ ] 
implying that monetary rewards operate as the key mediator between education and life satisfaction. Hypothesis 1 is therefore not completely supported: despite the overall positive association, the contribution of education to life satisfaction disappears once labor market outcomes, especially income levels, are taken into account.

More nuanced structures are detected when considering country-level educational expansion and skills diffusion (see Table 4). To test Hypothesis 2, Model 3 adds these societal conditions and their interactions with individual-level educational attainment to Model 1 , in which labor market outcomes are not accounted for. While the positive coefficient of individual-level tertiary education remains significant at the $1 \%$ level $\left(\gamma_{10}=0.771\right)$, its interaction term with skills diffusion demonstrates a negative sign $\left(\gamma_{12}=-0.023\right)$. This suggests the overall linkage between education and life satisfaction deteriorates in societies where the level of skills diffusion is relatively high. However, the diminishing power of educational attainment is not explicitly observed in relation to educational expansion (i.e., $\gamma_{11}$ is negative but not statistically significant). The same structure is confirmed when the cross-cohort differences in the degree of educational expansion and skills diffusion within countries are employed instead of their status quo in Model 5 (see Table 5) (i.e., $\gamma_{12}=-0.017$ and statistically significant at the $0.1 \%$ level whereas $\gamma_{11}$ is insignificant).

Meanwhile, in Model 4 that incorporates individual-level economic statuses (Table 4), the negative coefficient of the interaction term between skills diffusion and tertiary degrees is no longer substantial albeit statistically significant at the $10 \%$ level $\left(\gamma_{12}=-0.008\right)^{7}$. Given the possibility that the contribution of education to SWB is substantially mediated by income levels, this result is aligned with recent sociological arguments that skills diffusion would undermine the monetary value of individuals' educational credentials (Araki, 2020), thus hindering the link between education and life satisfaction especially when labor market outcomes are not controlled for. Yet, it is also worthy of note that $\gamma_{12}$ is $-0.017 /-0.009$ and significant at the $5 \%$ level in a model incorporating only skills diffusion without educational expansion (“Appendix in Table 12") and in Model 6 where the country-level educational conditions are replaced with the cross-cohort variation (Table 5), respectively. Hypothesis 2 is thus partially supported as with Hypothesis 1: the positive association between tertiary education and SWB remains despite the higher level of educational expansion in a given society but deteriorates due to skills diffusion.

Herein, in respect of Hypothesis 3, Models 3 to 6 consistently show an interesting result. While educational expansion does not demonstrate any substantial signs, the coefficient of skills diffusion (regardless of whether its measure is the status quo or the cross-cohort variation) is positive at the $0.1 \%$ significance level in all models $\left(\gamma_{02}=0.102\right.$ in Model 3; 0.076 in Model 4; 0.077 in Model 5; and 0.056 in Model 6). This linkage is robust even when (1) adjusting for other societal-level conditions such as GDP, inequality, labor security, and safety in "Appendix in Table 10" $\left(\gamma_{02}=0.051\right.$ and significant at the $1 \%$ level $)$;

\footnotetext{
7 Note that the coefficient of individual-level education is not statistically significant in this model, and hence its power is not so variable in the first place regardless of societal conditions.
} 
Table 4 Multilevel linear regression of life satisfaction

\begin{tabular}{|c|c|c|c|c|}
\hline \multirow[t]{2}{*}{ Predictor variables } & \multicolumn{2}{|l|}{ Model 3} & \multicolumn{2}{|l|}{ Model 4} \\
\hline & $\mathrm{B}$ & S.E. & $\mathrm{B}$ & S.E. \\
\hline Intercept & $4.051 * * *$ & 0.406 & $3.297 * * *$ & 0.274 \\
\hline \multicolumn{5}{|l|}{ Level one (individual) } \\
\hline Tertiary education & $0.771 * *$ & 0.237 & 0.307 & 0.177 \\
\hline Age & $-0.079 * * *$ & 0.007 & $-0.068 * * *$ & 0.006 \\
\hline Age squared & $0.001 * * *$ & 0.000 & $0.001 * * *$ & 0.000 \\
\hline Men & $-0.097 * * *$ & 0.034 & $-0.134 * * *$ & 0.032 \\
\hline \multicolumn{5}{|l|}{ Marital status (reference $=$ others) } \\
\hline Legally married & $0.494 * * *$ & 0.045 & $0.381 * * *$ & 0.045 \\
\hline Legally registered civil union & $0.436^{* * *}$ & 0.096 & $0.365^{* * * *}$ & 0.102 \\
\hline Legally separated & $-0.471 * * *$ & 0.090 & $-0.325 * *$ & 0.099 \\
\hline Legally divorced/dissolved & $-0.130^{*}$ & 0.055 & -0.012 & 0.053 \\
\hline Widowed/partner died & -0.025 & 0.092 & 0.037 & 0.088 \\
\hline Living with children & -0.063 & 0.035 & 0.022 & 0.030 \\
\hline Trust & $0.163 * * *$ & 0.007 & $0.136^{* * *}$ & 0.007 \\
\hline Religion or denomination & $0.098 *$ & 0.042 & $0.115^{* *}$ & 0.034 \\
\hline \multicolumn{5}{|l|}{ Voluntary/charitable activity (reference $=$ never) } \\
\hline At least once a week & $0.288 * * *$ & 0.051 & $0.250 * * *$ & 0.048 \\
\hline At least once a month & $0.233 * * *$ & 0.047 & $0.178 * * *$ & 0.043 \\
\hline At least once every three months & $0.186 * * *$ & 0.049 & $0.113^{*}$ & 0.045 \\
\hline At least once every six months & 0.139 & 0.078 & 0.077 & 0.073 \\
\hline Less often & 0.042 & 0.045 & 0.015 & 0.040 \\
\hline \multicolumn{5}{|l|}{ Health status (reference $=$ very bad) } \\
\hline Very good & $3.033 * * *$ & 0.141 & $2.507 * * *$ & 0.138 \\
\hline Good & $2.626^{* * *}$ & 0.120 & $2.159 * * *$ & 0.120 \\
\hline Fair & $1.947 * * *$ & 0.131 & $1.617 * * *$ & 0.135 \\
\hline $\mathrm{Bad}$ & $1.071 * * *$ & 0.146 & $0.962 * * *$ & 0.146 \\
\hline \multicolumn{5}{|l|}{ Main activity (reference $=$ others) } \\
\hline Paid work & & & -0.073 & 0.040 \\
\hline Education & & & -0.045 & 0.078 \\
\hline Unemployed/looking for a job & & & $-0.521 * *$ & 0.182 \\
\hline Unemployed/not looking for a job & & & -0.658 & 0.420 \\
\hline Permanently sick/disabled & & & -0.155 & 0.139 \\
\hline Retired & & & -0.003 & 0.050 \\
\hline Community/military service & & & -0.970 & 0.611 \\
\hline Housework/looking after others & & & -0.069 & 0.093 \\
\hline \multicolumn{5}{|l|}{ Income $($ reference $=$ very difficult $)$} \\
\hline Comfortable & & & $2.086^{* * * *}$ & 0.107 \\
\hline Coping & & & $1.606^{* * *}$ & 0.085 \\
\hline Difficult & & & $0.818 * * *$ & 0.065 \\
\hline \multicolumn{5}{|l|}{ Cross-level interactions } \\
\hline Tertiary education $*$ educational expansion & -0.011 & 0.007 & -0.006 & 0.005 \\
\hline Tertiary education $*$ skills diffusion & $-0.023^{* *}$ & 0.009 & -0.013 & 0.007 \\
\hline
\end{tabular}


Table 4 (continued)

\begin{tabular}{|c|c|c|c|c|}
\hline \multirow[t]{2}{*}{ Predictor variables } & \multicolumn{2}{|l|}{ Model 3} & \multicolumn{2}{|l|}{ Model 4} \\
\hline & B & S.E. & B & S.E. \\
\hline \multicolumn{5}{|l|}{ Level two (country) } \\
\hline Educational expansion & -0.004 & 0.012 & -0.003 & 0.009 \\
\hline Skills diffusion & $0.102 * * *$ & 0.021 & $0.076^{* * * *}$ & 0.016 \\
\hline \multicolumn{5}{|l|}{ Variance (random effect) } \\
\hline Covariance structure (intercept) & 0.257 & & 0.133 & \\
\hline Tertiary education & 0.052 & & 0.028 & \\
\hline \multicolumn{5}{|l|}{ Model fit } \\
\hline AIC & $203,066.0$ & & $199,489.3$ & \\
\hline
\end{tabular}

Data are weighted using post-stratification weights.

$* * * p<0.001, * * p<0.01, * p<0.05$ [two tailed] [N: Individual $=48,247$, Country $=24$ ]

and (2) incorporating several levels of educational attainment in "Appendix in Table 13" $\left(\gamma_{02}=0.064 \text { and significant at the } 0.1 \% \text { level }\right)^{8}$. These results suggest that people in highly skilled societies are more likely than those living in countries where the skills level as such or its cross-cohort progress is relatively low/limited to report higher life satisfaction, regardless of individual-level attributes and societal-level conditions. Indeed, Fig. 1 indicates a striking link between the level of skills diffusion (horizontal axis) and the average score of life satisfaction (vertical axis) across countries. Although this figure simply plots the two measures, it is evident that societal-level skills diffusion and the aggregate cognitive happiness level are strongly correlated $(r=0.75)$. Hypothesis 3 is therefore supported only in terms of the function of skills diffusion, whereas the association between educational expansion and SWB is not confirmed. The potential mechanism behind this positive link and its implications are discussed in the following section after summarizing the main findings.

Importantly, the aforementioned results are confirmed by all robustness checks, including the replacement of the outcome variable with the happiness scale ("Appendix in Table 6"), the employment of the multilevel ordered logistic regression model ("Appendix in Table 7"), the exclusion of respondents aged below 30 ("Appendix in Table 8"), and the

\footnotetext{
8 Alongside the consistency with the main argument, "Appendix in Table 13" also shows some interesting results concerning the cross-level interaction terms. While the main effects of three individuals' educational qualifications are insignificant, the interaction between tertiary degrees and the extent of educational expansion is negative and statistically significant at the 5\% level. This suggests, when considering the relative value of tertiary degrees as compared to lower secondary education and below, its contribution to SWB becomes small in conjunction with its diminishing scarcity (i.e., the value as a positional good). In the meantime, the interactions between the extent of skills diffusion and upper secondary/post-secondary non-tertiary education indicate positive signs at the $1 \%$ and $0.1 \%$ significance levels, respectively. One may therefore interpret the significant devaluation of tertiary education due to skills diffusion confirmed in the main models is substantially attributed to the intensified contribution of upper secondary and post-secondary non-tertiary education. This further corroborates the said argument that skills diffusion devalues high credentials as such and promotes meritocratic rewards allocation, through which individuals with lower educational qualifications are likely to gain higher SWB as they can compete for economic rewards based on their skills rather than being excluded due to the relatively low nominal levels of their credentials.
} 
Table 5 Multilevel linear regression of life satisfaction

\begin{tabular}{|c|c|c|c|c|}
\hline \multirow[t]{2}{*}{ Predictor Variables } & \multicolumn{2}{|l|}{ Model 5} & \multicolumn{2}{|l|}{ Model 6} \\
\hline & $\mathrm{B}$ & S.E. & $\mathrm{B}$ & S.E. \\
\hline Intercept & $4.260 * * *$ & $* 0.271$ & $3.529 * * *$ & $* 0.265$ \\
\hline \multicolumn{5}{|l|}{ Level one (individual) } \\
\hline Tertiary education & $0.346^{* * *}$ & 0.106 & 0.047 & 0.087 \\
\hline Age & $-0.079 * * *$ & $* 0.007$ & $-0.068 * * *$ & $* 0.006$ \\
\hline Age squared & $0.001 * * *$ & $* 0.000$ & $0.001 * * *$ & $* 0.000$ \\
\hline Men & $-0.097 * *$ & 0.035 & $-0.134 * * *$ & $* 0.032$ \\
\hline \multicolumn{5}{|l|}{ Marital status (reference $=$ others) } \\
\hline Legally married & $0.494 * * *$ & $* 0.045$ & $0.382 * * *$ & $* 0.045$ \\
\hline Legally registered civil union & $0.437 * * *$ & $* 0.096$ & $0.366 * * *$ & $* 0.102$ \\
\hline Legally separated & $-0.472 * * *$ & $* 0.090$ & $-0.325 * *$ & $* 0.099$ \\
\hline Legally divorced/dissolved & $-0.129 *$ & 0.055 & -0.011 & 0.053 \\
\hline Widowed/partner died & -0.024 & 0.092 & 0.038 & 0.088 \\
\hline Living with children & -0.063 & 0.035 & 0.021 & 0.030 \\
\hline Trust & $0.163 * * *$ & $* 0.007$ & $0.136^{* * *}$ & $* 0.007$ \\
\hline Religion or denomination & $0.098 *$ & 0.042 & $0.114 * *$ & $* 0.034$ \\
\hline \multicolumn{5}{|l|}{ Voluntary/charitable activity (reference $=$ never) } \\
\hline At least once a week & $0.288 * * *$ & $* 0.051$ & $0.250 * * *$ & $* 0.048$ \\
\hline At least once a month & $0.233 * * *$ & $* 0.047$ & $0.178 * * *$ & $* 0.043$ \\
\hline At least once every three months & $0.186^{* * *}$ & $* 0.049$ & $0.113 *$ & $* 0.045$ \\
\hline At least once every six months & 0.139 & 0.078 & 0.077 & 0.073 \\
\hline Less often & 0.042 & 0.044 & 0.015 & 0.039 \\
\hline \multicolumn{5}{|l|}{ Health status (reference $=$ very bad) } \\
\hline Very good & $3.032 * * *$ & $* 0.141$ & $2.507 * * *$ & $* 0.138$ \\
\hline Good & $2.626^{* * *}$ & $* 0.120$ & $2.159 * * *$ & $* 0.120$ \\
\hline Fair & $1.947 * * *$ & $* 0.130$ & $1.616 * * *$ & $* 0.135$ \\
\hline $\mathrm{Bad}$ & $1.071 * * *$ & $* 0.146$ & $0.962 * * *$ & $* 0.146$ \\
\hline \multicolumn{5}{|l|}{ Main activity (reference $=$ others) } \\
\hline Paid work & & & -0.073 & 0.040 \\
\hline Education & & & -0.044 & 0.078 \\
\hline Unemployed/looking for a job & & & $-0.520 * *$ & $* 0.182$ \\
\hline Unemployed/not looking for a job & & & -0.659 & 0.420 \\
\hline Permanently sick/disabled & & & -0.154 & 0.139 \\
\hline Retired & & & -0.002 & 0.050 \\
\hline Community/military service & & & -0.970 & 0.610 \\
\hline Housework/looking after others & & & -0.069 & 0.093 \\
\hline \multicolumn{5}{|l|}{ Income (reference $=$ very difficult) } \\
\hline Comfortable & & & $2.087 * * *$ & $* 0.107$ \\
\hline Coping & & & $1.606^{* * *}$ & $* 0.085$ \\
\hline Difficult & & & $0.818^{* * *}$ & $* 0.065$ \\
\hline \multicolumn{5}{|l|}{ Cross-level interactions } \\
\hline Tertiary education * cross-cohort difference in EE & 0.002 & 0.005 & 0.001 & 0.005 \\
\hline Tertiary education $*$ cross-cohort difference in SD & $-0.017 * * *$ & $* 0.005$ & $-0.009 *$ & $* 0.004$ \\
\hline
\end{tabular}


Table 5 (continued)

\begin{tabular}{|c|c|c|c|c|}
\hline \multirow[t]{2}{*}{ Predictor Variables } & \multicolumn{2}{|l|}{ Model 5} & \multicolumn{2}{|l|}{ Model 6} \\
\hline & B & S.E. & B & S.E. \\
\hline \multicolumn{5}{|l|}{ Level two (country) } \\
\hline Cross-cohort difference in educational expansion (EE) & -0.004 & 0.012 & -0.007 & 0.012 \\
\hline Cross-cohort difference in skills diffusion (SD) & \multicolumn{2}{|c|}{$0.077 * * * 0.015$} & \multicolumn{2}{|c|}{$0.056 * * * 0.008$} \\
\hline \multicolumn{5}{|l|}{ Variance (random effect) } \\
\hline Covariance structure (intercept) & \multicolumn{2}{|l|}{0.249} & \multicolumn{2}{|l|}{0.134} \\
\hline Tertiary education & \multicolumn{2}{|l|}{0.066} & \multicolumn{2}{|l|}{0.033} \\
\hline \multicolumn{5}{|l|}{ Model fit } \\
\hline AIC & \multicolumn{2}{|l|}{$203,069.2$} & \multicolumn{2}{|l|}{$199,492.0$} \\
\hline
\end{tabular}

Data are weighted using post-stratification weights.

$* * * p<0.001,{ }^{* *} p<0.01,{ }^{*} p<0.05$ [two tailed] [N: Individual $=48,247$, Country $=24$ ]

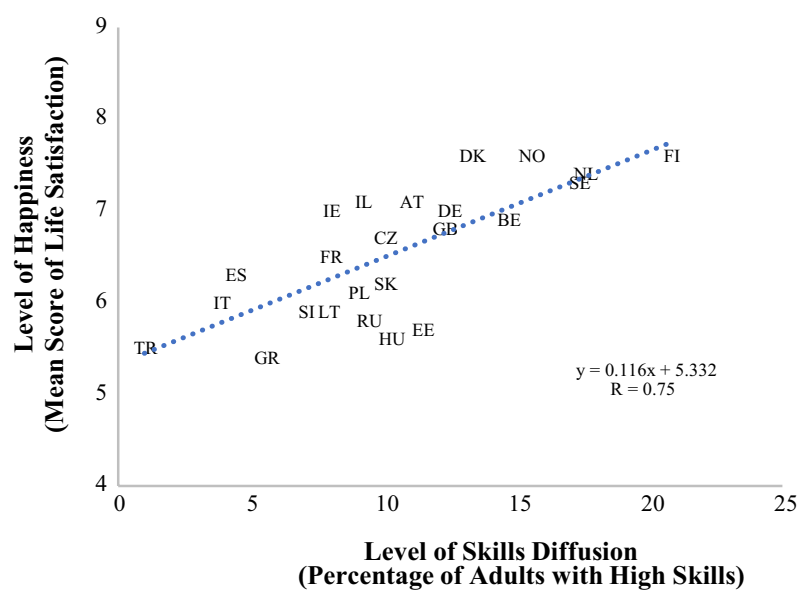

Fig. 1 The association between the level of skills diffusion and happiness in European countries. Note: The horizontal axis is the level of skills diffusion quantified by the mean of the percentage of PIAAC participants with literacy proficiency level 4 or 5 and that with numeracy proficiency level 4 or 5 . The vertical axis is the latest figure of life satisfaction shown in OECD.Stat (i.e., the mean score of life satisfaction measured by the 0-10 Cantril Ladder between 2015 and 2017). Each abbreviation indicates as follows: AT: Austria, BE: Belgium, CZ: Czech Republic, DK: Denmark, EE: Estonia, FI: Finland, FR: France, DE: Germany, GR: Greece, HU: Hungary, IE: Ireland, IL: Israel, IT: Italy, LT: Lithuania, NL: Netherlands, NO: Norway, PL: Poland, RU: Russian Federation, SK: Slovak Republic, SI: Slovenia, ES: Spain, SE: Sweden, TR: Turkey, GB: United Kingdom. Source: OECD (2019) and OECD.Stat (http://stats.oecd.org/) [Accessed: 20 January 2021] 
exclusion of Turkey whose individual-level data were collected in 2008 ("Appendix in Table 9"), among others.

\section{Discussions and Conclusion}

This article sheds light on the association between education and happiness. While the vast literature has investigated this agenda focusing on individual-level indicators in specific societies and/or cohorts, the present paper pays close attention to societal-level educational expansion and skills diffusion, examining primarily two questions: (1) how the influence of individuals' education differs depending on educational expansion and skills diffusion; and (2) how these two societal conditions collectively affect SWB of individuals in a direct manner. To this end, the following hypotheses are tested via cross-country multilevel regression analyses: Hypothesis 1-there is a positive link between education and happiness at the individual level, even after controlling for economic statuses; Hypothesis 2the association between education and happiness at the individual level is not undermined due to societal-level educational expansion and skills diffusion; Hypothesis 3-societallevel educational expansion and skills diffusion are positively associated with individuals' happiness.

Multilevel regression analyses, using the OECD country-level data alongside the ESS data for more than 48,000 individuals in 24 countries, confirm the significant overall association between educational attainment and life satisfaction at the individual level. However, once labor market outcomes (especially income levels) are accounted for, this positive relationship is no longer detected (i.e., Hypothesis 1 is supported only when economic rewards are not controlled for). This means, given that education generally leads to better occupations/incomes and that these rewards substantially affect people's life satisfaction, one may assume educational attainment contributes to SWB substantially via labor market outcomes. This also means, the internal contribution of education (i.e., learning activities as such promote satisfaction) is not explicitly observed.

In terms of the mutability due to societal-level educational conditions, the positive association between education and life satisfaction is undermined by skills diffusion rather than educational expansion. That is, the advantage of possessing a tertiary degree is likely to be smaller in societies where the proportion of highly skilled human resources is relatively large (i.e., Hypothesis 2 is partly wrong in the sense that the contribution of education diminishes alongside skills diffusion). This result is consistent with prior research that has suggested skills diffusion would promote the formation of meritocratic society, in which monetary returns to educational credentials as such progressively decline (Araki, 2020). Put differently, in highly skilled societies, educated individuals face the diminishing economic value of their high credentials, and consequently it becomes difficult to maintain relatively higher levels of life satisfaction as compared to less educated counterparts. One may also argue this is the consequence of the declining scarcity of tertiary degrees as positional goods (Nikolaev, 2016; Salinas-Jiménez et al., 2011).

Herein, the salient finding of this study is the significant link between societal-level skills diffusion and happiness (i.e., Hypothesis 3 is supported only in relation to skills diffusion). Regardless of analytic models (including the Appendices as well as Models 3-6 in the main manuscript), skills diffusion per se demonstrates a substantially positive association with life satisfaction even after adjusting for other key country-level and 
individual-level predictors. Indeed, Fig. 1 clearly indicates a strong positive correlation between the average level of life satisfaction and the degree of skills diffusion at the societal level (i.e., highly skilled societies are more likely than less skilled ones to show higher levels of SWB).

Although further examination is required to claim causality, the aforementioned result is aligned with recent sociological arguments that skills diffusion operates in a way that promotes meritocratic social systems. That is, one may assume skills diffusion enables societies to allocate various rewards on the basis of merits rather than socio-economic backgrounds and/or nominal educational credentials, making people feel more satisfied with (or at least encouraging them to accept) the current statuses. Put differently, "warming up" and "cooling out" (or "holding steady") (Alexander et al., 2008) in terms of status attainment" better operate in highly skilled societies.

One may argue that skills diffusion merely reflects other societal characteristics and works as a proxy for macroeconomy as well as quality, fairness, and efficiency of social systems. Yet, given that the analysis result is robust even when adjusting for such societal conditions as GDP and Gini coefficients ("Appendix in Table 10"), skills diffusion per se is assumed to be the key to promoting life satisfaction. In particular, considering the insignificant influence of the Gini index, one may further argue it is not the status quo (i.e., the extent of social equality) but the process (i.e., the extent to which rewards are allocated in a meritocratic way) that matters most: people are more likely to accept the current statuses when feeling the allocation process, rather than the consequence in itself, is fair, thus resulting in higher SWB.

As such, this study provides a new account for research on education and happiness with particular attention to societal-level skills diffusion as well as educational expansion. To develop the aforementioned discussion, future work needs to address several agendas. Firstly, country-specific longitudinal analyses are necessary. The present paper uses (1) the difference in the share of highly educated/skilled human resources across countries and (2) its cross-cohort variation within countries as the measure of educational expansion/ skills diffusion. However, to better explain the link between education and SWB when considering the function of societal-level skills diffusion as well as educational expansion in a dynamic way, it is essential to conduct country-specific and cross-country longitudinal analyses, preferably using panel data for more robust causal inference.

Secondly, the heterogeneity across social backgrounds should be investigated. Although fundamental predictors are taken into account as controls in the analysis, one may assume the relationship between education and happiness varies according to such backgrounds as age, gender, and ethnicity. Likewise, as regards individuals' education, it is worthwhile to explore the difference across types of credentials including fields of study and prestige of education institutions. This approach would be an attempt to analyze not only the average level of happiness but its variance.

Thirdly, individual-level skills are essential to be incorporated. Although they are not examined in the present paper due to the lack of data, it is important to elucidate how the association between individuals' skills and SWB changes in response to societal-level skills diffusion as well as educational expansion. In doing so, multiple types of skills in addition to the one measured by PIAAC (i.e., information processing skills) are worthy of examination.

\footnotetext{
9 Note that Alexander and colleagues, as with the vast literature, used these terms concerning educational aspiration rather than labor market outcomes.
} 
Finally, wider regions/countries along with the target countries of ESS should be investigated to verify the generalizability of the aforementioned findings. Herein, cross-country analyses and country-specific approaches are both meaningful in better understanding broader trends and detailed implications.

In summary, this article examines the nuanced relationship between education and happiness with particular attention to societal-level educational expansion and skills diffusion. Consequently, in addition to confirming some findings suggested by prior research, one notable structure is detected: the significant link between skills diffusion and life satisfaction. This means, although individual-level education is not necessarily the key to SWB when controlling for labor market outcomes, the accumulation of highly skilled human resources in a given society would collectively enhance people's satisfaction, possibly via fostering the meritocratic process of rewards allocation (rather than the status quo of social equality as well as macroeconomy). This interpretation is still hypothetical, and one question needs to be further scrutinized in an empirical way: why skills diffusion contributes to people's happiness over time and how their relationship differs across societies. With this potential for future research, the aforementioned findings in tandem with the theoretical and analytic framework significantly contribute to developing scholarship and social policy on education and happiness.

\section{Appendix}

See Tables 6, 7, 8, 9, 10, 11, 12, 13 . 
Table 6 Multilevel linear regression of happiness

\begin{tabular}{|c|c|c|}
\hline \multirow[t]{2}{*}{ Predictor variables } & \multicolumn{2}{|l|}{ Model A1 } \\
\hline & $\mathrm{B}$ & S.E. \\
\hline Intercept & $3.851 * * *$ & 0.302 \\
\hline \multicolumn{3}{|l|}{ Level one (individual) } \\
\hline Tertiary education & 0.159 & 0.159 \\
\hline Age & $-0.054 * * *$ & 0.004 \\
\hline Age squared & $0.001 * * *$ & 0.000 \\
\hline Men & $-0.198 * * *$ & 0.027 \\
\hline \multicolumn{3}{|l|}{ Marital status (reference $=$ others) } \\
\hline Legally married & $0.436^{* * *}$ & 0.041 \\
\hline Legally registered civil union & $0.364 * * *$ & 0.092 \\
\hline Legally separated & $-0.235^{* *}$ & 0.084 \\
\hline Legally divorced/dissolved & -0.049 & 0.036 \\
\hline Widowed/partner died & $-0.218^{* *}$ & 0.075 \\
\hline Living with children & $0.090^{* *}$ & 0.029 \\
\hline Trust & $0.110 * * *$ & 0.007 \\
\hline Religion or denomination & $0.097^{* *}$ & 0.029 \\
\hline \multicolumn{3}{|l|}{ Voluntary/charitable activity (reference $=$ never) } \\
\hline At least once a week & $0.212 * * *$ & 0.031 \\
\hline At least once a month & $0.138 * * *$ & 0.036 \\
\hline At least once every three months & $0.126^{* *}$ & 0.036 \\
\hline At least once every six months & 0.082 & 0.047 \\
\hline Less often & 0.014 & 0.031 \\
\hline \multicolumn{3}{|l|}{ Health status (reference $=$ very bad) } \\
\hline Very good & $2.393 * * *$ & 0.136 \\
\hline Good & $1.987 * * *$ & 0.123 \\
\hline Fair & $1.541 * * *$ & 0.118 \\
\hline $\mathrm{Bad}$ & $0.909 * * *$ & 0.114 \\
\hline \multicolumn{3}{|l|}{ Main activity (reference $=$ others) } \\
\hline Paid work & -0.057 & 0.034 \\
\hline Education & -0.040 & 0.086 \\
\hline Unemployed/looking for a job & -0.230 & 0.134 \\
\hline Unemployed/not looking for a job & -0.264 & 0.313 \\
\hline Permanently sick/disabled & 0.025 & 0.114 \\
\hline Retired & 0.015 & 0.045 \\
\hline Community/military service & -1.074 & 0.719 \\
\hline Housework/looking after others & 0.039 & 0.060 \\
\hline \multicolumn{3}{|l|}{ Income $($ reference $=$ very difficult $)$} \\
\hline Comfortable & $1.579 * * *$ & 0.071 \\
\hline Coping & $1.255^{* * *}$ & 0.059 \\
\hline Difficult & $0.676^{* * *}$ & 0.041 \\
\hline \multicolumn{3}{|l|}{ Cross-level interactions } \\
\hline Tertiary education * educational expansion & -0.002 & 0.006 \\
\hline Tertiary education $*$ skills diffusion & -0.013 & 0.010 \\
\hline
\end{tabular}


Table 6 (continued)

Predictor variables

Model A1

B

S.E.

Level two (country)

Educational expansion

0.006

0.010

Skills diffusion

$0.055^{* *}$

0.019

Variance (random effect)

Covariance structure (intercept)

0.121

Tertiary education

0.033

The outcome variable is the answer (0-10 scale) to the question about happiness "Taking all things together, how happy would you say you are?" instead of the one about life satisfaction. The sample size is smaller than the main analysis by 336 due to the missing data.

$* * * p<0.001, * * p<0.01, * p<0.05$ [two tailed] [N: Individual $=47,911$, Country $=24$ ] 
Table 7 Multilevel ordered logistic regression of life satisfaction

\begin{tabular}{|c|c|c|}
\hline \multirow[t]{2}{*}{ Predictor variables } & \multicolumn{2}{|l|}{ Model A2 } \\
\hline & B & S.E. \\
\hline \multicolumn{3}{|l|}{ Threshold } \\
\hline Cut point 1 & -1.495 & 0.274 \\
\hline Cut point 2 & -0.990 & 0.274 \\
\hline Cut point 3 & -0.345 & 0.273 \\
\hline Cut point 4 & 0.382 & 0.273 \\
\hline Cut point 5 & 0.915 & 0.273 \\
\hline Cut point 6 & 1.849 & 0.274 \\
\hline Cut point 7 & 2.433 & 0.274 \\
\hline Cut point 8 & 3.346 & 0.274 \\
\hline Cut point 9 & 4.661 & 0.274 \\
\hline Cut point 10 & 5.855 & 0.274 \\
\hline \multicolumn{3}{|l|}{ Level one (individual) } \\
\hline Tertiary education & 0.269 & 0.173 \\
\hline Age & $-0.063 * * *$ & 0.003 \\
\hline Age squared & $0.001 * * *$ & 0.000 \\
\hline Men & $-0.144 * * *$ & 0.017 \\
\hline \multicolumn{3}{|l|}{ Marital status (reference $=$ others) } \\
\hline Legally married & $0.384 * * *$ & 0.025 \\
\hline Legally registered civil union & $0.370 * * *$ & 0.093 \\
\hline Legally separated & -0.191 & 0.115 \\
\hline Legally divorced/dissolved & 0.030 & 0.035 \\
\hline Widowed/partner died & 0.038 & 0.040 \\
\hline Living with children & 0.018 & 0.020 \\
\hline Trust & $0.127 * * *$ & 0.004 \\
\hline Religion or denomination & $0.130 * * *$ & 0.019 \\
\hline \multicolumn{3}{|c|}{ Voluntary/charitable activity $($ reference $=$ never $)$} \\
\hline At least once a week & $0.294 * * *$ & 0.036 \\
\hline At least once a month & $0.176^{* * *}$ & 0.035 \\
\hline At least once every three months & $0.111^{* *}$ & 0.041 \\
\hline At least once every six months & 0.062 & 0.037 \\
\hline Less often & 0.007 & 0.027 \\
\hline \multicolumn{3}{|l|}{ Health status (reference $=$ very bad) } \\
\hline Very good & $2.323 * * *$ & 0.082 \\
\hline Good & $1.863 * * *$ & 0.080 \\
\hline Fair & $1.344 * * *$ & 0.080 \\
\hline Bad & $0.809 * * *$ & 0.083 \\
\hline \multicolumn{3}{|l|}{ Main activity (reference $=$ others) } \\
\hline Paid work & $-0.085^{*}$ & 0.032 \\
\hline Education & -0.027 & 0.074 \\
\hline Unemployed/looking for a job & $-0.451^{* * *}$ & 0.118 \\
\hline Unemployed/not looking for a job & $-0.576^{*}$ & 0.223 \\
\hline Permanently sick/disabled & 0.011 & 0.124 \\
\hline Retired & -0.005 & 0.051 \\
\hline
\end{tabular}


Table 7 (continued)

Predictor variables

Model A2

B

$-1.294$

0.738

Community/military service

Housework/looking after others

$-0.023$

0.059

Income (reference $=$ very difficult)

Comfortable

$1.871 * * *$

0.037

Coping

$1.321 * * *$

0.033

Difficult

$0.606 * * *$

0.033

Cross-level interactions

Tertiary education * educational expansion

Tertiary education * skills diffusion

$-0.006$

0.005

$-0.015$

0.011

Level two (country)

Educational expansion

Skills diffusion

$-0.002$

$0.068 * * *$

0.018

Variance (random effect)

Covariance structure (Intercept)

0.125

Tertiary education

A multilevel ordered logistic regression is conducted instead of a multilevel linear regression. $* * * p<0.001, * * p<0.01, * p<0.05$ [two tailed] [N: Individual $=48,247$, Country $=24$ ] 
Table 8 Multilevel linear regression of life satisfaction (respondents aged 30 and over)

\begin{tabular}{|c|c|c|}
\hline \multirow[t]{2}{*}{ Predictor variables } & \multicolumn{2}{|l|}{ Model A3 } \\
\hline & B & S.E. \\
\hline Intercept & $2.594 * * *$ & 0.362 \\
\hline \multicolumn{3}{|l|}{ Level one (individual) } \\
\hline Tertiary education & 0.288 & 0.213 \\
\hline Age & $-0.042 * * *$ & 0.008 \\
\hline Age squared & $0.000^{* * *}$ & 0.000 \\
\hline Men & $-0.113 * *$ & 0.033 \\
\hline \multicolumn{3}{|l|}{ Marital status (reference $=$ others) } \\
\hline Legally married & $0.357 * * *$ & 0.049 \\
\hline Legally registered civil union & $0.416^{* * *}$ & 0.099 \\
\hline Legally separated & $-0.360 * *$ & 0.111 \\
\hline Legally divorced/dissolved & -0.032 & 0.054 \\
\hline Widowed/partner died & 0.069 & 0.085 \\
\hline Living with children & 0.017 & 0.031 \\
\hline Trust & $0.134 * * *$ & 0.006 \\
\hline Religion or denomination & $0.136^{* * *}$ & 0.034 \\
\hline \multicolumn{3}{|l|}{ Voluntary/charitable activity (reference $=$ never) } \\
\hline At least once a week & $0.270^{* * *}$ & 0.044 \\
\hline At least once a month & $0.159 * *$ & 0.050 \\
\hline At least once every three months & 0.096 & 0.057 \\
\hline At least once every six months & 0.062 & 0.065 \\
\hline Less often & 0.014 & 0.043 \\
\hline \multicolumn{3}{|l|}{ Health status (reference $=$ very bad) } \\
\hline Very good & $2.418 * * *$ & 0.143 \\
\hline Good & $2.104 * * *$ & 0.122 \\
\hline Fair & $1.583 * * *$ & 0.134 \\
\hline $\mathrm{Bad}$ & $0.939 * * *$ & 0.146 \\
\hline \multicolumn{3}{|l|}{ Main activity (reference $=$ others) } \\
\hline Paid work & -0.073 & 0.045 \\
\hline Education & 0.283 & 0.203 \\
\hline Unemployed/looking for a job & $-0.430 *$ & 0.193 \\
\hline Unemployed/not looking for a job & -0.734 & 0.540 \\
\hline Permanently sick/disabled & -0.187 & 0.157 \\
\hline Retired & -0.012 & 0.048 \\
\hline Housework/looking after others & -0.063 & 0.101 \\
\hline \multicolumn{3}{|l|}{ Income $($ reference $=$ very difficult $)$} \\
\hline Comfortable & $2.205 * * *$ & 0.115 \\
\hline Coping & $1.686^{* * *}$ & 0.086 \\
\hline Difficult & $0.845^{* * *}$ & 0.069 \\
\hline \multicolumn{3}{|l|}{ Cross-level interactions } \\
\hline Tertiary education $*$ educational expansion & -0.004 & 0.007 \\
\hline Tertiary education $*$ skills diffusion & $-0.018^{*}$ & 0.009 \\
\hline \multicolumn{3}{|l|}{ Level two (country) } \\
\hline Educational expansion & -0.004 & 0.011 \\
\hline
\end{tabular}


Table 8 (continued)

\begin{tabular}{llc}
\hline Predictor variables & \multicolumn{2}{l}{ Model A3 } \\
\cline { 2 - 3 } & $\mathrm{B}$ & S.E. \\
\hline Skills diffusion & $0.079^{* * *}$ & 0.019 \\
Variance (random effect) & & \\
Covariance structure (intercept) & & 0.174 \\
Tertiary education & 0.044 & \\
\hline
\end{tabular}

The respondents are limited to individuals aged 30 and over. The analytic model is the same as Model 4 in the main manuscript.

$* * * p<0.001, * * p<0.01, * p<0.05$ [two tailed] [N: Individual $=38,527$, Country $=24]$ 
Table 9 Multilevel linear regression of life satisfaction (without Turkey)

\begin{tabular}{|c|c|c|}
\hline \multirow[t]{2}{*}{ Predictor variables } & \multicolumn{2}{|l|}{ Model A4 } \\
\hline & B & S.E. \\
\hline Intercept & $3.274 * * *$ & 0.323 \\
\hline \multicolumn{3}{|l|}{ Level one (individual) } \\
\hline Tertiary education & 0.307 & 0.177 \\
\hline Age & $-0.070 * * *$ & 0.006 \\
\hline Age squared & $0.001 * * *$ & 0.000 \\
\hline Men & $-0.115^{* * *}$ & 0.028 \\
\hline \multicolumn{3}{|l|}{ Marital status (reference $=$ others) } \\
\hline Legally married & $0.394 * * *$ & 0.045 \\
\hline Legally registered civil union & $0.373 * * *$ & 0.104 \\
\hline Legally separated & $-0.310^{* *}$ & 0.099 \\
\hline Legally divorced/dissolved & 0.004 & 0.052 \\
\hline Widowed/partner died & 0.056 & 0.091 \\
\hline Living with children & 0.020 & 0.032 \\
\hline Trust & $0.136 * * *$ & 0.007 \\
\hline Religion or denomination & $0.113 * *$ & 0.034 \\
\hline \multicolumn{3}{|l|}{ Voluntary/charitable activity (reference $=$ never) } \\
\hline At least once a week & $0.251 * * *$ & 0.048 \\
\hline At least once a month & $0.178 * * *$ & 0.044 \\
\hline At least once every three months & $0.114 *$ & 0.045 \\
\hline At least once every six months & 0.077 & 0.073 \\
\hline Less often & 0.014 & 0.039 \\
\hline \multicolumn{3}{|l|}{ Health status (reference = very bad) } \\
\hline Very good & $2.469 * * *$ & 0.135 \\
\hline Good & $2.118 * * *$ & 0.115 \\
\hline Fair & $1.573 * * *$ & 0.130 \\
\hline $\mathrm{Bad}$ & $0.910 * * *$ & 0.139 \\
\hline \multicolumn{3}{|l|}{ Main activity (reference $=$ others) } \\
\hline Paid work & -0.070 & 0.040 \\
\hline Education & -0.045 & 0.078 \\
\hline Unemployed/looking for a job & $-0.516^{*}$ & 0.183 \\
\hline Unemployed/not looking for a job & -0.654 & 0.418 \\
\hline Permanently sick/disabled & -0.150 & 0.138 \\
\hline Retired & -0.001 & 0.050 \\
\hline Housework/looking after others & -0.987 & 0.609 \\
\hline \multicolumn{3}{|l|}{ Income (reference $=$ very difficult $)$} \\
\hline Comfortable & $2.089 * * *$ & 0.115 \\
\hline Coping & $1.606 * * *$ & 0.093 \\
\hline Difficult & $0.817 * * *$ & 0.072 \\
\hline \multicolumn{3}{|l|}{ Cross-level interactions } \\
\hline Tertiary education $*$ educational expansion & -0.006 & 0.005 \\
\hline Tertiary education $*$ skills diffusion & -0.013 & 0.007 \\
\hline \multicolumn{3}{|l|}{ Level two (country) } \\
\hline Educational expansion & -0.002 & 0.010 \\
\hline
\end{tabular}


Table 9 (continued)

\begin{tabular}{lcc}
\hline Predictor variables & Model A4 & \\
\cline { 3 - 3 } & $\mathrm{B}$ & S.E. \\
\hline Skills diffusion & $0.080^{* * * *}$ & 0.017 \\
Variance (random effect) & & \\
Covariance structure (intercept) & 0.137 & \\
Tertiary education & 0.029 & \\
\hline
\end{tabular}

Turkey is excluded from the analysis. The analytic model is the same as Model 4 in the main manuscript. ${ }^{* * *} p<0.001,{ }^{* *} p<0.01, * p<0.05$ [two tailed] [N: Individual $=45,965$, Country $=23$ ] 
Table 10 Multilevel linear regression of life satisfaction (with additional country-level variables)

\begin{tabular}{|c|c|c|}
\hline \multirow[t]{2}{*}{ Predictor variables } & \multicolumn{2}{|l|}{ Model A5 } \\
\hline & B & S.E. \\
\hline Intercept & 4.208 & 5.118 \\
\hline \multicolumn{3}{|l|}{ Level one (individual) } \\
\hline Tertiary education & 0.309 & 0.177 \\
\hline Age & $-0.069 * * *$ & 0.006 \\
\hline Age squared & $0.001 * * *$ & 0.000 \\
\hline Men & $-0.134 * * *$ & 0.032 \\
\hline \multicolumn{3}{|l|}{ Marital status (reference $=$ others) } \\
\hline Legally married & $0.381 * * *$ & 0.045 \\
\hline Legally registered civil union & $0.361 * * *$ & 0.102 \\
\hline Legally separated & $-0.326^{* *}$ & 0.098 \\
\hline Legally divorced/dissolved & -0.012 & 0.053 \\
\hline Widowed/partner died & 0.038 & 0.088 \\
\hline Living with children & 0.022 & 0.030 \\
\hline Trust & $0.136 * * *$ & 0.007 \\
\hline Religion or denomination & $0.115 * *$ & 0.034 \\
\hline \multicolumn{3}{|l|}{ Voluntary/charitable activity (reference $=$ never) } \\
\hline At least once a week & $0.250 * * *$ & 0.048 \\
\hline At least once a month & $0.178 * * *$ & 0.043 \\
\hline At least once every three months & $0.114 *$ & 0.045 \\
\hline At least once every six months & 0.078 & 0.073 \\
\hline Less often & 0.017 & 0.040 \\
\hline \multicolumn{3}{|l|}{ Health status (reference $=$ very bad) } \\
\hline Very good & $2.505 * * *$ & 0.139 \\
\hline Good & $2.158 * * *$ & 0.120 \\
\hline Fair & $1.617 * * *$ & 0.135 \\
\hline $\mathrm{Bad}$ & $0.963 * * *$ & 0.146 \\
\hline \multicolumn{3}{|l|}{ Main activity (reference $=$ others) } \\
\hline Paid work & -0.073 & 0.040 \\
\hline Education & -0.045 & 0.078 \\
\hline Unemployed/looking for a job & $-0.521 * *$ & 0.183 \\
\hline Unemployed/not looking for a job & -0.658 & 0.419 \\
\hline Permanently sick/disabled & -0.155 & 0.139 \\
\hline Retired & -0.003 & 0.050 \\
\hline Housework/looking after others & -0.968 & 0.614 \\
\hline \multicolumn{3}{|l|}{ Income $($ reference $=$ very difficult $)$} \\
\hline Comfortable & $2.084 * * *$ & 0.108 \\
\hline Coping & $1.606^{* * *}$ & 0.085 \\
\hline Difficult & $0.819 * * *$ & 0.065 \\
\hline \multicolumn{3}{|l|}{ Cross-level interactions } \\
\hline Tertiary education $*$ educational expansion & -0.006 & 0.005 \\
\hline Tertiary education $*$ skills diffusion & -0.013 & 0.007 \\
\hline \multicolumn{3}{|l|}{ Level two (country) } \\
\hline Educational expansion & 0.013 & 0.015 \\
\hline
\end{tabular}


Table 10 (continued)

\begin{tabular}{lcr}
\hline Predictor variables & Model A5 & S.E. \\
\cline { 2 - 3 } & B & 0.019 \\
\hline Skills diffusion & $0.051^{* *}$ & 0.084 \\
GDP per capita (/10,000) & -0.080 & 1.820 \\
Gini index & -0.507 & 0.022 \\
Dwellings without basic facilities & -0.030 & 0.027 \\
Long-term unemployment & -0.039 & 0.029 \\
Quality of support network & 0.008 & 0.007 \\
Voter turnout & 0.013 & 0.047 \\
Life expectancy & -0.028 & 0.010 \\
Air pollution & 0.014 & 0.085 \\
Homicide rate & -0.096 & \\
Variance (random effect) & & 0.137 \\
Covariance structure (intercept) & 0.029 &
\end{tabular}

The analytic model is the same as Model 4 in the main manuscript except for additional country-level variables.

$* * * p<0.001, * * p<0.01, * p<0.05$ [two tailed] [N: Individual $=48,247$, Country $=24$ ] 
Table 11 Multilevel linear regression of life satisfaction (with occupations and income included separately)

\begin{tabular}{|c|c|c|c|c|}
\hline \multirow[t]{2}{*}{ Predictor variables } & \multicolumn{2}{|l|}{ Model A6-1 } & \multicolumn{2}{|l|}{ Model A6-2 } \\
\hline & $\mathrm{B}$ & S.E. & $\mathrm{B}$ & S.E. \\
\hline Intercept & $4.067 * * *$ & 0.407 & $3.284 * * *$ & 0.272 \\
\hline \multicolumn{5}{|l|}{ Level one (individual) } \\
\hline Tertiary education & $0.764 * *$ & 0.233 & 0.308 & 0.178 \\
\hline Age & $-0.079 * * *$ & 0.007 & $-0.069 * * *$ & 0.006 \\
\hline Age squared & $0.001 * * *$ & 0.000 & $0.001 * * *$ & 0.000 \\
\hline Men & $-0.099 * *$ & 0.035 & $-0.131 * * *$ & 0.032 \\
\hline \multicolumn{5}{|l|}{ Marital status (reference $=$ others) } \\
\hline Legally married & $0.490 * * *$ & 0.046 & $0.382 * * *$ & 0.044 \\
\hline Legally registered civil union & $0.433 * * *$ & 0.097 & $0.367 * * *$ & 0.100 \\
\hline Legally separated & $-0.467 * * *$ & 0.089 & $-0.326^{* *}$ & 0.100 \\
\hline Legally divorced/dissolved & $-0.129^{*}$ & 0.055 & -0.013 & 0.053 \\
\hline Widowed/partner died & -0.029 & 0.092 & 0.040 & 0.088 \\
\hline Living with children & -0.059 & 0.035 & 0.019 & 0.030 \\
\hline Trust & $0.163 * * *$ & 0.007 & $0.136 * * *$ & 0.007 \\
\hline Religion or denomination & $0.098^{*}$ & 0.042 & $0.116 * *$ & 0.034 \\
\hline \multicolumn{5}{|l|}{ Voluntary/charitable activity (reference $=$ never) } \\
\hline At least once a week & $0.289 * * *$ & 0.052 & $0.248 * * *$ & 0.048 \\
\hline At least once a month & $0.234 * * *$ & 0.047 & $0.175 * * *$ & 0.044 \\
\hline At least once every three months & $0.183 * * *$ & 0.049 & $0.112 *$ & 0.045 \\
\hline At least once every six months & 0.137 & 0.078 & 0.077 & 0.073 \\
\hline Less often & 0.040 & 0.044 & 0.015 & 0.040 \\
\hline \multicolumn{5}{|l|}{ Health status (reference $=$ very bad $)$} \\
\hline Very good & $3.019 * * *$ & 0.142 & $2.510 * * *$ & 0.137 \\
\hline Good & $2.616^{* * * *}$ & 0.121 & $2.160 * * *$ & 0.119 \\
\hline Fair & $1.940 * * *$ & 0.132 & $1.617 * * *$ & 0.135 \\
\hline Bad & $1.070 * * *$ & 0.146 & $0.960 * * *$ & 0.146 \\
\hline \multicolumn{5}{|l|}{ Main activity (reference $=$ others) } \\
\hline Paid work & 0.014 & 0.045 & & \\
\hline Education & 0.015 & 0.094 & & \\
\hline Unemployed/looking for a job & $-0.927 * * *$ & 0.233 & & \\
\hline Unemployed/not looking for a job & -0.830 & 0.478 & & \\
\hline Permanently sick/disabled & -0.276 & 0.148 & & \\
\hline Retired & 0.036 & 0.062 & & \\
\hline Community/military service & -1.150 & 0.698 & & \\
\hline Housework/looking after others & -0.101 & 0.098 & & \\
\hline \multicolumn{5}{|l|}{ Income (reference $=$ very difficult $)$} \\
\hline Comfortable & & & $2.094 * * *$ & 0.110 \\
\hline Coping & & & $1.613 * * *$ & 0.087 \\
\hline Difficult & & & $0.823 * * *$ & 0.066 \\
\hline \multicolumn{5}{|l|}{ Cross-level interactions } \\
\hline Tertiary education $*$ educational expansion & -0.010 & 0.007 & -0.006 & 0.005 \\
\hline Tertiary education $*$ skills diffusion & $-0.023 * *$ & 0.009 & -0.013 & 0.007 \\
\hline
\end{tabular}


Table 11 (continued)

\begin{tabular}{|c|c|c|c|c|}
\hline \multirow[t]{2}{*}{ Predictor variables } & \multicolumn{2}{|l|}{ Model A6-1 } & \multicolumn{2}{|l|}{ Model A6-2 } \\
\hline & $\mathrm{B}$ & S.E. & $\mathrm{B}$ & S.E. \\
\hline \multicolumn{5}{|l|}{ Level two (country) } \\
\hline Educational expansion & -0.004 & 0.012 & -0.003 & 0.009 \\
\hline Skills diffusion & $0.102 * * *$ & 0.021 & $0.076^{* * *}$ & 0.016 \\
\hline \multicolumn{5}{|l|}{ Variance (random effect) } \\
\hline Covariance structure (intercept) & 0.257 & & 0.132 & \\
\hline Tertiary education & 0.051 & & 0.029 & \\
\hline
\end{tabular}

The analytic model is based on Model 4 in the main manuscript, and individual-level "Main Activity" and "Income" are included separately.

$* * * p<0.001, * * p<0.01, * p<0.05$ [two tailed] [N: Individual $=48,247$, Country $=24$ ] 
Table 12 Multilevel linear regression of life satisfaction (with educational expansion and skills diffusion included separately)

\begin{tabular}{|c|c|c|c|c|}
\hline \multirow[t]{2}{*}{ Predictor variables } & \multicolumn{2}{|l|}{ Model A7-1 } & \multicolumn{2}{|l|}{ Model A7-2 } \\
\hline & $\mathrm{B}$ & S.E. & $\mathrm{B}$ & S.E. \\
\hline Intercept & $3.584 * * *$ & 0.391 & $3.236 * * *$ & 0.196 \\
\hline \multicolumn{5}{|l|}{ Level one (individual) } \\
\hline Tertiary education & 0.227 & 0.167 & 0.152 & 0.096 \\
\hline Age & $-0.069 * * *$ & 0.006 & $-0.068 * * *$ & 0.006 \\
\hline Age squared & $0.001 * * *$ & 0.000 & $0.001 * * *$ & 0.000 \\
\hline Men & $-0.134 * * *$ & 0.032 & $-0.134 * * *$ & 0.032 \\
\hline \multicolumn{5}{|l|}{ Marital status (reference $=$ others) } \\
\hline Legally married & $0.382 * * *$ & 0.045 & $0.381 * * *$ & 0.045 \\
\hline Legally registered civil union & $0.368 * * *$ & 0.102 & $0.364 * * *$ & 0.102 \\
\hline Legally separated & $-0.326 * *$ & 0.099 & $-0.325^{* *}$ & 0.099 \\
\hline Legally divorced/dissolved & -0.010 & 0.053 & -0.012 & 0.053 \\
\hline Widowed/partner died & 0.039 & 0.088 & 0.037 & 0.088 \\
\hline Living with children & 0.021 & 0.030 & 0.022 & 0.030 \\
\hline Trust & $0.136 * * *$ & 0.007 & $0.136 * * *$ & 0.007 \\
\hline Religion or denomination & $0.112 * *$ & 0.034 & $0.115 * *$ & 0.034 \\
\hline \multicolumn{5}{|l|}{ Voluntary/charitable activity (reference $=$ never) } \\
\hline At least once a week & $0.250 * * *$ & 0.048 & $0.250 * * *$ & 0.048 \\
\hline At least once a month & $0.178 * * *$ & 0.043 & $0.177 * * *$ & 0.043 \\
\hline At least once every three months & $0.113^{*}$ & 0.045 & $0.113 * *$ & 0.045 \\
\hline At least once every six months & 0.077 & 0.073 & 0.077 & 0.073 \\
\hline Less often & 0.015 & 0.040 & 0.014 & 0.040 \\
\hline \multicolumn{5}{|l|}{ Health status (reference $=$ very bad) } \\
\hline Very good & $2.507 * * *$ & 0.138 & $2.507 * * *$ & 0.138 \\
\hline Good & $2.160 * * *$ & 0.120 & $2.159 * * *$ & 0.120 \\
\hline Fair & $1.617 * * *$ & 0.135 & $1.617 * * *$ & 0.135 \\
\hline Bad & $0.962 * * *$ & 0.146 & $0.962 * * *$ & 0.146 \\
\hline \multicolumn{5}{|l|}{ Main activity (reference $=$ others) } \\
\hline Paid work & -0.073 & 0.040 & -0.073 & 0.040 \\
\hline Education & -0.044 & 0.078 & -0.045 & 0.078 \\
\hline Unemployed/looking for a job & $-0.520 * *$ & 0.183 & $-0.520 * * *$ & 0.182 \\
\hline Unemployed/not looking for a job & -0.658 & 0.419 & -0.658 & 0.420 \\
\hline Permanently sick/disabled & -0.153 & 0.139 & -0.155 & 0.139 \\
\hline Retired & -0.003 & 0.050 & -0.003 & 0.050 \\
\hline Community/military service & -0.976 & 0.611 & -0.967 & 0.610 \\
\hline Housework/looking after others & -0.068 & 0.093 & -0.069 & 0.093 \\
\hline \multicolumn{5}{|l|}{ Income (reference $=$ very difficult $)$} \\
\hline Comfortable & $2.087 * * *$ & 0.107 & $2.087 * * *$ & 0.107 \\
\hline Coping & $1.607 * * *$ & 0.085 & $1.606 * * *$ & 0.085 \\
\hline Difficult & $0.818 * * *$ & 0.065 & $0.818 * * *$ & 0.065 \\
\hline \multicolumn{5}{|l|}{ Cross-level interactions } \\
\hline Tertiary education * educational expansion & -0.008 & 0.005 & & \\
\hline Tertiary education $*$ skills diffusion & & & $-0.017 *$ & 0.007 \\
\hline
\end{tabular}


Table 12 (continued)

\begin{tabular}{|c|c|c|c|c|}
\hline \multirow[t]{2}{*}{ Predictor variables } & \multicolumn{2}{|c|}{ Model A7-1 } & \multicolumn{2}{|l|}{ Model A7-2 } \\
\hline & $\mathrm{B}$ & S.E. & B & S.E. \\
\hline \multicolumn{5}{|l|}{ Level two (country) } \\
\hline Educational expansion & 0.014 & 0.010 & & \\
\hline Skills diffusion & & & $0.073 * * *$ & 0.012 \\
\hline \multicolumn{5}{|l|}{ Variance (random effect) } \\
\hline Covariance structure (intercept) & 0.226 & & 0.134 & \\
\hline Tertiary education & 0.032 & & 0.031 & \\
\hline
\end{tabular}

The analytic model is based on Model 4 in the main manuscript, and country-level "Educational Expansion" and "Skills Diffusion" are included separately.

$* * * p<0.001, * * p<0.01, * p<0.05$ [two tailed] [N: Individual $=48,247$, Country $=24$ ] 
Table 13 Multilevel linear regression of life satisfaction (with several levels of educational attainment at the individual level)

\begin{tabular}{|c|c|c|}
\hline \multirow[t]{2}{*}{ Predictor variables } & \multicolumn{2}{|l|}{ Model A8 } \\
\hline & B & S.E \\
\hline Intercept & 3.241 & 0.272 \\
\hline \multicolumn{3}{|l|}{ Level one (individual) } \\
\hline \multicolumn{3}{|c|}{ Education $($ reference $=$ lower secondary and below) } \\
\hline Upper secondary & -0.153 & 0.137 \\
\hline Post-secondary Non-tertiary & -0.239 & 0.168 \\
\hline Tertiary & 0.228 & 0.196 \\
\hline Age & $-0.065 * * *$ & 0.006 \\
\hline Age squared & $0.001 * * *$ & 0.000 \\
\hline Men & $-0.135 * * *$ & 0.032 \\
\hline \multicolumn{3}{|l|}{ Marital status (reference $=$ others) } \\
\hline Legally married & $0.382 * * *$ & 0.044 \\
\hline Legally registered civil union & $0.370^{* * *}$ & 0.097 \\
\hline Legally separated & $-0.331^{* *}$ & 0.099 \\
\hline Legally divorced/dissolved & -0.009 & 0.053 \\
\hline Widowed/partner died & 0.032 & 0.088 \\
\hline Living with children & 0.019 & 0.031 \\
\hline Trust & $0.137 * * *$ & 0.007 \\
\hline Religion or denomination & $0.113^{* *}$ & 0.033 \\
\hline \multicolumn{3}{|c|}{ Voluntary/charitable activity $($ reference $=$ never $)$} \\
\hline At least once a week & $0.255^{* * *}$ & 0.048 \\
\hline At least once a month & $0.185^{* * *}$ & 0.043 \\
\hline At least once every three months & $0.120^{* *}$ & 0.045 \\
\hline At least once every six months & 0.083 & 0.072 \\
\hline Less often & 0.020 & 0.040 \\
\hline \multicolumn{3}{|l|}{ Health status (reference $=$ very bad) } \\
\hline Very good & $2.526^{* * *}$ & 0.137 \\
\hline Good & $2.173 * * *$ & 0.119 \\
\hline Fair & $1.631 * * *$ & 0.134 \\
\hline $\mathrm{Bad}$ & $0.964 * * *$ & 0.146 \\
\hline \multicolumn{3}{|l|}{ Main activity (reference $=$ others) } \\
\hline Paid work & -0.072 & 0.039 \\
\hline Education & -0.049 & 0.077 \\
\hline Unemployed/looking for a job & $-0.524 * *$ & 0.185 \\
\hline Unemployed/not looking for a job & -0.650 & 0.423 \\
\hline Permanently sick/disabled & -0.168 & 0.135 \\
\hline Retired & 0.000 & 0.051 \\
\hline Housework/looking after others & -0.918 & 0.579 \\
\hline \multicolumn{3}{|l|}{ Income $($ reference $=$ very difficult $)$} \\
\hline Comfortable & $2.108 * * *$ & 0.108 \\
\hline Coping & $1.626^{* * *}$ & 0.085 \\
\hline Difficult & $0.831 * * *$ & 0.065 \\
\hline
\end{tabular}


Table 13 (continued)

\begin{tabular}{lll}
\hline Predictor variables & Model A8 & \\
\cline { 3 - 3 } & $\mathrm{B}$ & $\mathrm{S} . \mathrm{E}$ \\
\hline Cross-level interactions & & 0.005 \\
Upper secondary * educational expansion & -0.006 & 0.005 \\
Post-secondary non-tertiary * educational expansion & -0.008 & 0.006 \\
Tertiary * educational expansion & $-0.011^{*}$ & 0.007 \\
Upper secondary * skills diffusion & $0.020^{* *}$ & 0.006 \\
Post-secondary non-tertiary * skills diffusion & $0.031^{* * *}$ & 0.008 \\
Tertiary * skills diffusion & 0.001 & \\
Level two (country) & & 0.010 \\
Educational expansion & 0.003 & 0.016 \\
Skills diffusion & $0.064^{* * *}$ & \\
Variance (random effect) & & \\
Covariance structure (intercept) & 0.126 & \\
Upper secondary & 0.015 & \\
Post-secondary non-tertiary & 0.000 & \\
Tertiary & 0.025 & \\
\hline
\end{tabular}

The analytic model is the same as Model 4 in the main manuscript except for additional individual-level educational variables.

$* * * p<0.001, * * p<0.01, * p \mathrm{~s}<0.05$ [two tailed] [N: Individual $=48,247$, Country $=24$ ]

Acknowledgements I would like to thank Takehiko Kariya, Richard Breen, Hugh Whittaker, Oriel Sullivan, Heather Kirkup, three anonymous reviewers, and the editors (especially David Bartram) for their invaluable comments and suggestions.

Funding This research does not receive any funding support.

Data Availability Data are available from the following website. https://www.europeansocialsurvey.org/

Code Availability Codes are available from the author upon request.

\section{Declarations}

Conflict of interest The author declare that they have no conflict of interest.

Open Access This article is licensed under a Creative Commons Attribution 4.0 International License, which permits use, sharing, adaptation, distribution and reproduction in any medium or format, as long as you give appropriate credit to the original author(s) and the source, provide a link to the Creative Commons licence, and indicate if changes were made. The images or other third party material in this article are included in the article's Creative Commons licence, unless indicated otherwise in a credit line to the material. If material is not included in the article's Creative Commons licence and your intended use is not permitted by statutory regulation or exceeds the permitted use, you will need to obtain permission directly from the copyright holder. To view a copy of this licence, visit http://creativecommons.org/licenses/by/4.0/. 


\section{References}

Aassve, A., Goisis, A., \& Sironi, M. (2012). Happiness and childbearing across Europe. Social Indicators Research, 108(1), 65-86.

Acemoglu, D., \& Autor, D. (2011). Skills tasks and technologies: Implications for employment and earnings. Handbook of Labor Economics, 4b, 1043-1171.

Ai, C., \& Norton, E. C. (2003). Interaction terms in logit and probit models. Economics Letters, 80(1), $123-129$.

Akaeda, N. (2019). Contextual social trust and well-being inequality: From the perspectives of education and income. Journal of Happiness Studies, 21(8), 2957-2979.

Alexander, K., Bozick, R., \& Entwisle, D. (2008). Warming up, cooling out, or holding steady? Persistence and change in educational expectations after high school. Sociology of Education, 81(4), 371-396.

Araki, S. (2020). Educational expansion, skills diffusion, and the economic value of credentials and skills. American Sociological Review, 85(1), 128-175.

Bailey, R. (2009). Review of well-being, happiness and education. British Journal of Sociology of Education, 30(6), 795-802.

Bartram, D. (2021). Age and life satisfaction: Getting control variables under control. Sociology, 55(2), 421-437.

Bernstein, B. (1996). Pedagogy, symbolic control and identity: Theory, research, critique. Taylor \& Francis.

Bills, D. B. (2016). Congested credentials: The material and positional economies of schooling. Research in Social Stratification and Mobility, 43, 65-70.

Bol, T. (2015). Has education become more positional? Educational expansion and labour market outcomes, 1985-2007. Acta Sociologica, 58(2), 105-120.

Bol, T., Eller, C. C., van de Werfhorst, H. G., \& DiPrete, T. A. (2019). School-to-work linkages, educational mismatches, and labor market outcomes. American Sociological Review, 84(2), 275-307.

Borgen, N. T., \& Mastekaasa, A. (2018). Horizontal stratification of higher education: The relative importance of field of study, institution, and department for candidates' wages. Social Forces, 97(2), 531-558.

Bourdieu, P., \& Passeron, J.-C. (1977). Reproduction in education, society and culture. SAGE Publications.

Bowles, S., \& Gintis, H. (1976). Schooling in capitalist America: Educational reform and the contradictions of economic life. Routledge \& Kegan Paul.

Breen, R., Karlson, K. B., \& Holm, A. (2018). Interpreting and understanding logits, probits, and other nonlinear probability models. Annual Review of Sociology, 44, 39-54.

Brighouse, H. (2006). On education: Thinking in action. Routledge.

Brown, D. K. (2001). The social sources of educational credentialism: Status cultures, labor markets, and organizations. Sociology of Education, 74(2001), 19-34.

Brown, P. (2003). The opportunity trap: Education and employment in a global economy. European Educational Research Journal, 2(1), 141-179.

Chen, W. C. (2012). How education enhances happiness: comparison of mediating factors in four East Asian countries. Social Indicators Research, 106(1), 117-131.

Clark, A. E., \& Oswald, A. J. (1996). Satisfaction and comparison income. Journal of Public Economics, 61(3), 359-381.

Coleman, J., Campbell, E. Q., Hobson, C. J., McPartland, J., Mood, A. M., Weinfeld, F. D., \& York, R. L. (1966). Equality of educational opportunity. U.S. Government Printing Office.

Collins, R. (1979). The credential society: An historical sociology of education and stratification. Academic Press.

Cuñado, J., \& de Gracia, F. P. (2012). Does education affect happiness? Evidence for Spain. Social Indicators Research, 108(1), 185-96.

D’Ambrosio, C., Jäntti, M., \& Lepinteur, A. (2020). Money and happiness: Income, wealth and subjective well-being. Social Indicators Research, 148(1), 47-66.

Di Stasio, V. (2017). Who is ahead in the labor queue? Institutions' and employers' perspective on overeducation, undereducation, and horizontal mismatches. Sociology of Education, 90(2), 109-26.

Di Stasio, V., Bol, T., \& van de Werfhorst, H. G. (2016). What makes education positional? Institutions, overeducation and the competition for jobs. Research in Social Stratification and Mobility, $43,53-63$.

Diener, E. (2000). Subjective well-being. the science of happiness and a proposal for a national index. American Psychologist, 55(1), 34-43.

Diener, E., Ng, W., Harter, J., \& Arora, R. (2010). Wealth and happiness across the world: Material prosperity predicts life evaluation, whereas psychosocial prosperity predicts positive feeling. Journal of Personality and Social Psychology, 99(1), 52-61. 
Easterlin, R. A., McVey, L. A., Switek, M., Sawangfa, O., \& Zweig, J. S. (2010). The happiness-income paradox revisited. Proceedings of the National Academy of Sciences, 107(52), 22463-68.

Edling, C., Rydgren, J., \& Bohman, L. (2014). Faith or Social foci? Happiness, religion, and social networks in Sweden. European Sociological Review, 30(5), 615-626.

Ferrer-i-Carbonell, A., \& Frijters, P. (2004). How important is methodology for the estimates of the determinants of happiness? The Economic Journal, 114(497), 641-659.

Foucault, M. (1977). Discipline \& punish: The birth of the prison. Vintage Books.

Freire, P. (1972). Pedagogy of the oppressed. Penguin.

Frey, B., \& Stutzer, A. (2002). Happiness and economics: How the economy and institutions affect human well-being. Princeton University Press.

Goldin, C., \& Katz, L. F. (2008). The race between education and technology. Harvard University Press.

Haller, M., \& Hadler, M. (2006). How social relations and structures can produce happiness and unhappiness: An international comparative analysis. Social Indicators Research, 75(2), 169-216.

Hannum, E., Ishida, H., Park, H., \& Tam, T. (2019). Education in East Asian societies: Postwar expansion and the evolution of inequality. Annual Review of Sociology, 45(1), 625-647.

Hanushek, E. A., Schwerdt, G., Wiederhold, S., \& Woessmann, L. (2015). Returns to skills around the world: Evidence from PIAAC. European Economic Review, 73, 103-130.

Heisig, J. P., \& Schaeffer, M. (2019). Why you should always include a random slope for the lower-level variable involved in a cross-level interaction. European Sociological Review, 35(2), 258-279.

Helliwell, J. F. (2003). How's life? combining individual and national variables to explain subjective wellbeing. Economic Modelling, 20(2), 331-360.

Helliwell, J. F., Layard, R., Sachs, J., \& De Neve, J.-E. (Eds.). (2020). World happiness report 2020. Sustainable Development Solutions Network.

$\mathrm{Hu}, \mathrm{A}$. (2015). The changing happiness-enhancing effect of a college degree under higher education expansion: Evidence from China. Journal of Happiness Studies, 16(3), 669-685.

Illich, I. (1971). Deschooling society. Harper and Row.

Kahneman, D., \& Deaton, A. (2010). High income improves evaluation of life but not emotional well-being. Proceedings of the National Academy of Sciences, 107(38), 16489-16493.

Kelley, J., \& Evans, M. D. R. (2017). Societal inequality and individual subjective well-being: Results from 68 societies and over 200,000 individuals, 1981-2008. Social Science Research, 62, 1-23.

Lemieux, T. (2008). The changing nature of wage inequality. Journal of Population Economics, 21(1), 21-48.

Lim, C., \& Putnam, R. D. (2010). Religion, social networks, and life satisfaction. American Sociological Review, 75(6), 914-933.

Marginson, S. (2016). The worldwide trend to high participation higher education: Dynamics of social stratification in inclusive systems. Higher Education, 72, 413-434.

Michalos, A. C. (2008). Education, happiness and wellbeing. Social Indicators Research, 87(3), 347-366.

Möwisch, D., Brose, A., \& Schmiedek, F. (2021). Do Higher educated people feel better in everyday life? Insights from a day reconstruction method study. Social Indicators Research, 153, 227-250.

Ngoo, Y. T., Tey, N. P., \& Tan, E. C. (2015). Determinants of life satisfaction in Asia. Social Indicators Research, 124(1), 141-156.

Nikolaev, B. (2016). Does other people's education make us less happy? Economics of Education Review, $52,176-191$.

Nikolaev, B. (2018). Does higher education increase hedonic and eudaimonic happiness? Journal of Happiness Studies, 19, 483-504.

Novarese, M., \& Rizzello, S. (2005). Satisfaction and learning: An experimental game to measure happiness. In F. Parisi \& V. L. Smith (Eds.), The law and economics of irrational behavior (pp. 186207). Stanford University Press.

OECD. (2007). Understanding the social outcomes of learning. OECD Publishing.

OECD. (2014a). Education at a glance 2014: OECD indicators. OECD Publishing.

OECD. (2014b). How's life in your region?: Measuring regional and local well-being for policy making. OECD Publishing.

OECD. (2015). How's life? 2015: Measuring well-being. OECD Publishing.

OECD. (2019). Skills matter: Additional results from the survey of adult skills. OECD Publishing.

Oreopoulos, P., \& Salvanes, K. G. (2011). Priceless: The nonpecuniary benefits of schooling. Journal of Economic Perspectives, 25(1), 159-184.

Ortiz, L., \& Rodriguez-Menés, J. (2016). The positional value of education and its effect on general and technical fields of education: Educational expansion and occupational returns to education in Spain. European Sociological Review, 32(2), 216-237. 
Oulton, N. (2012). Hooray for GDP! (Vol. 30). Centre for Economic Performance, London School of Economics and Political Science.

Perelli-Harris, B., Hoherz, S., Lappegård, T., \& Evans, A. (2019). Mind the 'happiness' gap: The relationship between cohabitation, marriage, and subjective well-being in the United Kingdom, Australia, Germany, and Norway. Demography, 56(4), 1219-1246.

Posselt, J. R., \& Grodsky, E. (2017). Graduate education and social stratification. Annual Review of Sociology, 43, 353-378.

Powdthavee, N., Lekfuangfu, W. N., \& Wooden, M. (2015). What's the good of education on our overall quality of life? A simultaneous equation model of education and life satisfaction for Australia. Journal of Behavioral and Experimental Economics, 54, 10-21.

Rodríguez-Pose, A., \& von Berlepsch, V. (2014). Social capital and individual happiness in Europe. Journal of Happiness Studies, 15, 357-386.

Ruiu, G., \& Ruiu, M. L. (2019). The complex relationship between education and happiness: The case of highly educated individuals in Italy. Journal of Happiness Studies, 20(8), 2631-2653.

Salinas-Jiménez, M.M., Artés, J., \& Salinas-Jiménez, J. (2011). Education as a positional good: A life satisfaction approach. Social Indicators Research, 103(3), 409-426.

Salinas-Jiménez, M.M., Artés, J., \& Salinas-Jiménez, J. (2013). How do educational attainment and occupational and wage-earner statuses affect life satisfaction? A gender perspective study. Journal of Happiness Studies, 14(2), 367-388.

Shields, M. A., Price, S. W., \& Wooden, M. (2009). Life satisfaction and the economic and social characteristics of neighbourhoods. Journal of Population Economics, 22(2), 421-443.

Steptoe, A., Deaton, A., \& Stone, A. A. (2015). Subjective wellbeing, health, and ageing. The Lancet, $385,640-648$.

Stiglitz, J. E., Sen, A., \& Fitoussi, J.-P. (2009). Report by the commission on the measurement of economic performance and social progress. Commission on the Measurement of Economic Performance and Social Progress.

Sullivan, A., Parsons, S., Green, F., Wiggins, R. D., \& Ploubidis, G. (2018). Elite universities, fields of study and top salaries: Which degree will make you rich ? British Educational Research Journal, 44(4), 663-680.

Tholen, G. (2017). Symbolic closure: Towards a renewed sociological perspective on the relationship between higher education, credentials and the graduate labour market. Sociology, 51(5), 1067-1083.

Tsurumi, T., Yamaguchi, R., Kagohashi, K., \& Managi, S. (2020). Are cognitive, affective, and eudaimonic dimensions of subjective well-being differently related to consumption? Evidence from Japan. Journal of Happiness Studies. https://doi.org/10.1007/s10902-020-00327-4

United Nations. (2016). The sustainable development goals report 2016. United Nations.

van der Meer, P. H. (2014). Gender, unemployment and subjective well-being: Why being unemployed is worse for men than for women. Social Indicators Research, 115(1), 23-44.

van Zanden, J. L., Baten, J., D’Ercole, M. M., Rijpma, A., Smith, C., \& Timmer, M. (2014). How was life?: Global well-being since 1820. OECD Publishing.

Veenhoven, R. (2010). Capability and happiness: Conceptual difference and reality links. Journal of SocioEconomics, 39(3), 344-350.

World Bank. (2017). World development report 2018: Learning to realize education's promise. World Bank Publications.

Publisher's Note Springer Nature remains neutral with regard to jurisdictional claims in published maps and institutional affiliations. 